\title{
State of the Art of Low and Medium Voltage Direct Current (DC) Microgrids
}

\author{
Maria Fotopoulou (D), Dimitrios Rakopoulos*(D), Dimitrios Trigkas, Fotis Stergiopoulos, Orestis Blanas \\ and Spyros Voutetakis (D)
}

check for updates

Citation: Fotopoulou, M.; Rakopoulos, D.; Trigkas, D.; Stergiopoulos, F.; Blanas, O.; Voutetakis, S. State of the Art of Low and Medium Voltage Direct Current (DC) Microgrids. Energies 2021, 14 , 5595. https://doi.org/10.3390/ en14185595

Academic Editors: Aditya Shekhar and Laura Ramírez Elizondo

Received: 4 August 2021

Accepted: 30 August 2021

Published: 7 September 2021

Publisher's Note: MDPI stays neutral with regard to jurisdictional claims in published maps and institutional affiliations.

Copyright: (c) 2021 by the authors. Licensee MDPI, Basel, Switzerland. This article is an open access article distributed under the terms and conditions of the Creative Commons Attribution (CC BY) license (https:/ / creativecommons.org/licenses/by/ $4.0 /)$.
Chemical Process and Energy Resources Institute, Centre for Research and Technology Hellas, Thermi, GR-57001 Thessaloniki, Greece; fotopoulou@certh.gr (M.F.); dtrigkas@certh.gr (D.T.); foster@certh.gr (F.S.); blanas@certh.gr (O.B.); paris@certh.gr (S.V.)

* Correspondence: rakopoulos@certh.gr; Tel.: +30-210-6899-689

\begin{abstract}
Direct current (DC) microgrids (MG) constitute a research field that has gained great attention over the past few years, challenging the well-established dominance of their alternating current (AC) counterparts in Low Voltage (LV) (up to $1.5 \mathrm{kV}$ ) as well as Medium Voltage (MV) applications (up to $50 \mathrm{kV}$ ). The main reasons behind this change are: (i) the ascending amalgamation of Renewable Energy Sources (RES) and Battery Energy Storage Systems (BESS), which predominantly supply DC power to the energy mix that meets electrical power demand and (ii) the ascending use of electronic loads and other DC-powered devices by the end-users. In this sense, DC distribution provides a more efficient interface between the majority of Distributed Energy Resources (DER) and part of the total load of a MG. The early adopters of DC MGs include mostly buildings with high RES production, ships, data centers, electric vehicle (EV) charging stations and traction systems. However, the lack of expertise and the insufficient standards' framework inhibit their wider spread. This review paper presents the state of the art of LV and MV DC MGs in terms of advantages/disadvantages over their AC counterparts, their interface with the AC main grid, topologies, control, applications, ancillary services and standardization issues. Overall, the aim of this review is to highlight the possibilities provided by DC MG architectures as well as the necessity for a solid/inclusive regulatory framework, which is their main weakness.
\end{abstract}

Keywords: DC microgrid; architectures; applications; ancillary services; standards

\section{Introduction}

In electrical microgrids (MG), as in all sectors of modern technology and applications, the need for sustainability in terms of reducing the energy footprint is considered to be a major priority. In fact, according to the European Union (EU) targets of 2020, the greenhouse gas emissions need to be reduced by at least $55 \%$ by 2030, compared to 1990 levels [1]. In order for such goals to be achieved, the reduction in fossil fuel-based energy production is required. As an alternative, Renewable Energy Sources (RES) have proven to be a solution with minimal environmental impact of vital importance. Photovoltaic $(\mathrm{PV})$ systems, wind generators (WG), biomass and geothermal installations have penetrated the market over the past few decades, improving the energy mix that covers the electricity demand [2,3]. Nevertheless, a major drawback of many RES, is the intermittent production, due to the sources that they utilize. In order for the production to meet the demand curve, the utilization of Energy Storage Systems (ESS) is considered to be an effective solution. ESS typically include Battery Energy Storage Systems (BESS), flywheels, compressed air systems, etc. [4]. The most common, widely utilized ESS technology is the BESS, with advantages such as high controllability, fast response and geographical independence [5]. Subsequently, for sustainability-related reasons, the combination of distributed RES (especially PV systems and WGs) with BESS has created a new field of 
research and development, promoting the decarbonization, autonomy and cost efficiency of MGs [6].

However, the increasing integration of RES and ESS in the current energy mix does not only result to the rise of eco-friendly energy supply, but also to the rise of proliferation of DC systems, i.e., DC generation and DC storage units. In fact, some of the most widely utilized RES and ESS, such as PV and BESS, originally produce DC power (either as current or voltage sources), which is then converted to AC power through DC/AC power electronics converters in order to be injected to the AC distribution grid. Additionally, the same phenomenon is observed on the side of energy demand. More specifically, DC loads including electric vehicles (EVs), Light Emitting Diode (LED) systems, DC motors, data centers and other battery-based devices have penetrated the market following an ascending curve $[7,8]$. Yet, these devices too incorporate special converters that convert AC into DC power in order to function. Also, one should also have in mind that most of the electronics loads and devices are based on DC power. Taking the above facts into consideration, it is evident that traditional AC distribution needs to cope with the new developments, and innovative DC distribution challenges its dominance, as presented in Figure 1.

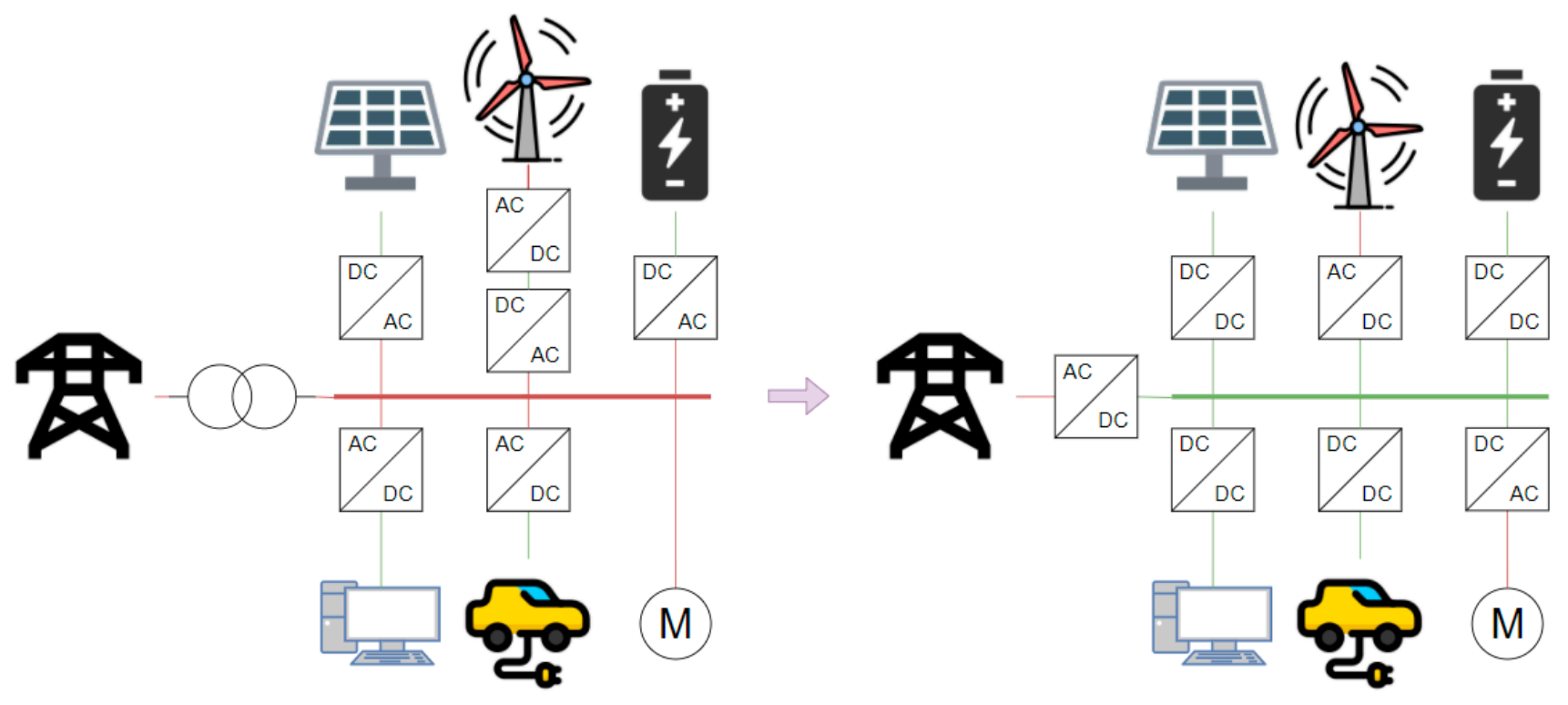

Figure 1. The transition from AC MGs to DC MGs.

Up until recently, DC power systems have been utilized mostly in High Voltage (HV) applications, predominantly for the purpose of power transmission over long distances, due to the low-power losses, high-power quality and cost efficiency that the High Voltage Direct Current (HVDC) transmission has to offer in such applications. This has been a milestone of DC power systems, as presented in the work of [9-13]. Nevertheless, since the necessary high-voltage, high-power and efficient power electronics and DC cables have only been developed during the past decades, the advantages of DC power systems have not been fully exploited in most sectors, especially at the Low Voltage (LV) (indicatively up to $1.5 \mathrm{kV}$ ) and Medium Voltage (MV) levels (indicatively up to $50 \mathrm{kV}$ ), leaving the dominance of power systems to AC architectures. Yet, the modern challenges for efficient integration of RES in the LV and MV levels have brought DC power to the spotlight. Low Voltage Direct Current (LVDC) as well as Medium Voltage Direct Current (MVDC) MGs constitute a modern field of research and development and have found applications in a variety of fields. However, there are still obstacles that the DC MGs have to overcome in order to be widely adopted, most significant of which is the lack of a sufficient standards' framework [14]. 
This review paper aims to present the state of the art of LV and MV DC MGs, including their advantages/disadvantages (Section 2), their implementation methods (i.e., possible interfaces with the main AC grid-Section 3, topologies-Section 4, control-Section 5), their most popular applications (Section 6), the ancillary services that they may provide to the main grid (Section 7) and their main obstacles as regards the market penetration (Section 8). Although, as revealed in the following sections, there is a number of relevant review papers on DC MGs, none of them addresses all of these issues, but rather discuss only a part of them. The purpose of this review is to provide an overall framework of the DC MG capabilities, addressing all their main aspects and highlighting their importance in future grids and power distribution applications.

\section{Advantages and Disadvantages of DC MGs}

The benefits of DC MG infrastructures, compared to their AC counterparts include:

- Easier integration of RES and ESS and reduction in primary energy consumption: A high proportion of RES and ESS produce DC power that would be more efficiently integrated in a DC MG than in an AC MG. Examples include PV, BESS and fuelcell systems. In a DC MG, the use of these sources' supply does not need to be converted from DC to AC. On the contrary, instead of DC/AC converters, DC/DC converters need to be implemented, which are more efficient and smaller, resulting in the reduction in primary energy consumption [15].

- More effective integration of DC loads: Distributing DC power to DC loads (e.g., from popular electronic devices to EVs) instead of converting it from AC to DC can lead to energy and cost savings from the aspect of the consumer. By skipping the $\mathrm{AC} / \mathrm{DC}$ conversion phase, losses are reduced, resulting in lower costs of energy. This modification could lead to substantial savings considering DC loads such as EVs, LED lights, data centers, electronic equipment, etc. [15].

- $\quad$ Easy enhancement of power quality and control of the MG: In DC MGs there are no harmonic oscillations or phase unbalances, which occur in AC MGs and undermine the power quality. Instead, the DC systems provide a "firewall" that prevents disturbances propagating from one network to another, improving the MGs' robustness [16,17]. Furthermore, since DC MGs operate only with active power, there is no need for reactive power control, in contrast with their AC counterparts [18].

- No need for synchronization: In DC systems there is no need to synchronize the grid-connected RES with the main AC grid. This can further reduce the operational complexity of the system [19]. On the other hand, in AC MGs the frequency needs to be regulated in order to be constantly kept equal to 50 or $60 \mathrm{~Hz}$ giving rise to stability issues.

- No skin effect: In DC systems there is no skin effect. This allows the current's flow through the entire distribution cable, not just the outer edges. As a result, DC distribution reduces losses and provides the possibility to use smaller cables for the same flow of current [19].

On the other hand, DC technologies have not been researched as much as their AC counterparts. This is attributed to the fact that the entire concept of electrical energy production, transmission and distribution has been built on AC technology, which provided the means to progress and develop more efficient, reliable and cost effective equipment. This means that the implementation of DC solutions has certain drawbacks such as:

- Lack of specific standards: In order for a system, such as the DC MG to be widely implemented, the definition of certain parameters, such as the voltage levels, need to be specified. Due to the fact that DC applications are not as widespread as AC applications, there is a general lack of standardized values regarding their function. This issue needs to be addressed, in order for the DC MGs to enter the worldwide market [20].

- Protection issues: In the case of DC power, there are protection issues that are not only related to the lack of standards but also to the specific nature of DC current. Specifically, 
breaking a functioning DC circuit is considered to be more difficult, compared to its $\mathrm{AC}$ counterpart, because there is no natural zero crossing of the current, to minimize the arc effect. Major research efforts are undertaken for the development of switchgear that can accommodate the secure disruption of DC voltages in the order of $\mathrm{kVs}$, with low cost, to enable the development of grid infrastructures $[18,19]$.

- Lack of expertise: The existing grids are most commonly AC-based. The AC technology is proven and mature, whereas DC technology is in a process to be established. This means that few specialists, grid developers and system operators have studied DC MGs extensively.

- Construction cost: The overall cost regarding the construction of AC MGs is lower than the respective cost for DC MGs. This occurs because the development of DC technologies, e.g., dedicated power converters, terminals, etc., is more recent and the innovation is integrated into the overall cost.

The comparison between DC and AC MGs is briefly presented in Table 1. Overall, the implementation of DC MGs appears to be a key driver in paving the way towards sustainability, efficiency and mitigation of the anthropogenic climate change. For their proper incorporation in the traditional AC grid and their establishment in the worldwide market, further research needs to be conducted for their proper design and function in terms of interface, topology and control.

Table 1. Comparison between DC and AC MGs (Data from $[15,18])$.

\begin{tabular}{ccc}
\hline & DC MG & AC MG \\
\hline Integration of RES and ESS & Effective & Not effective \\
\hline $\begin{array}{c}\text { Reduction in primary energy } \\
\text { consumption }\end{array}$ & Yes & No \\
\hline $\begin{array}{c}\text { Integration of DC loads } \\
\text { Power quality and control of } \\
\text { the MG }\end{array}$ & Effective & Not effective \\
\hline Synchronization & Easy & Complicated \\
\hline Frequency regulation & Not required & Required \\
\hline Skin effect & No frequency & Constant, equal to 50 or $60 \mathrm{~Hz}$ \\
\hline Standards & No & Yes \\
\hline Protection & Insufficient & Sufficient \\
\hline Expertise & Underdeveloped, expensive & $\begin{array}{c}\text { Fully developed, not } \\
\text { expensive }\end{array}$ \\
\hline Construction cost & Low & High \\
\hline
\end{tabular}

\section{Interface with the AC Grid}

The interconnection of the DC MG with the conventional AC power network is an issue of interest that has led to the emergence of a new research area over the past few years. In fact, several classifications have emerged regarding the interface of the conventional Medium Voltage Alternating Current (MVAC) grid with the DC grid [21]. To begin, it is important to state two fundamental types of interfaces, as presented in Figure 2: (a) those based on standard, separate converters, i.e., (1) and (2) and (b) those based on the concept of the Solid State Transformer (SST), i.e., (3), (4) and (5). An SST is an advanced, multi-stage power electronics device that enables the connection of grids with different voltage and frequency levels [22]. Its special configuration has advantages that do not exist in typical power transformers. In fact, the SST can provide DC ports that facilitate the integration of BESS, DC RES, DC loads and enables the implementation of power quality features, such as advanced control schemes [23]. 


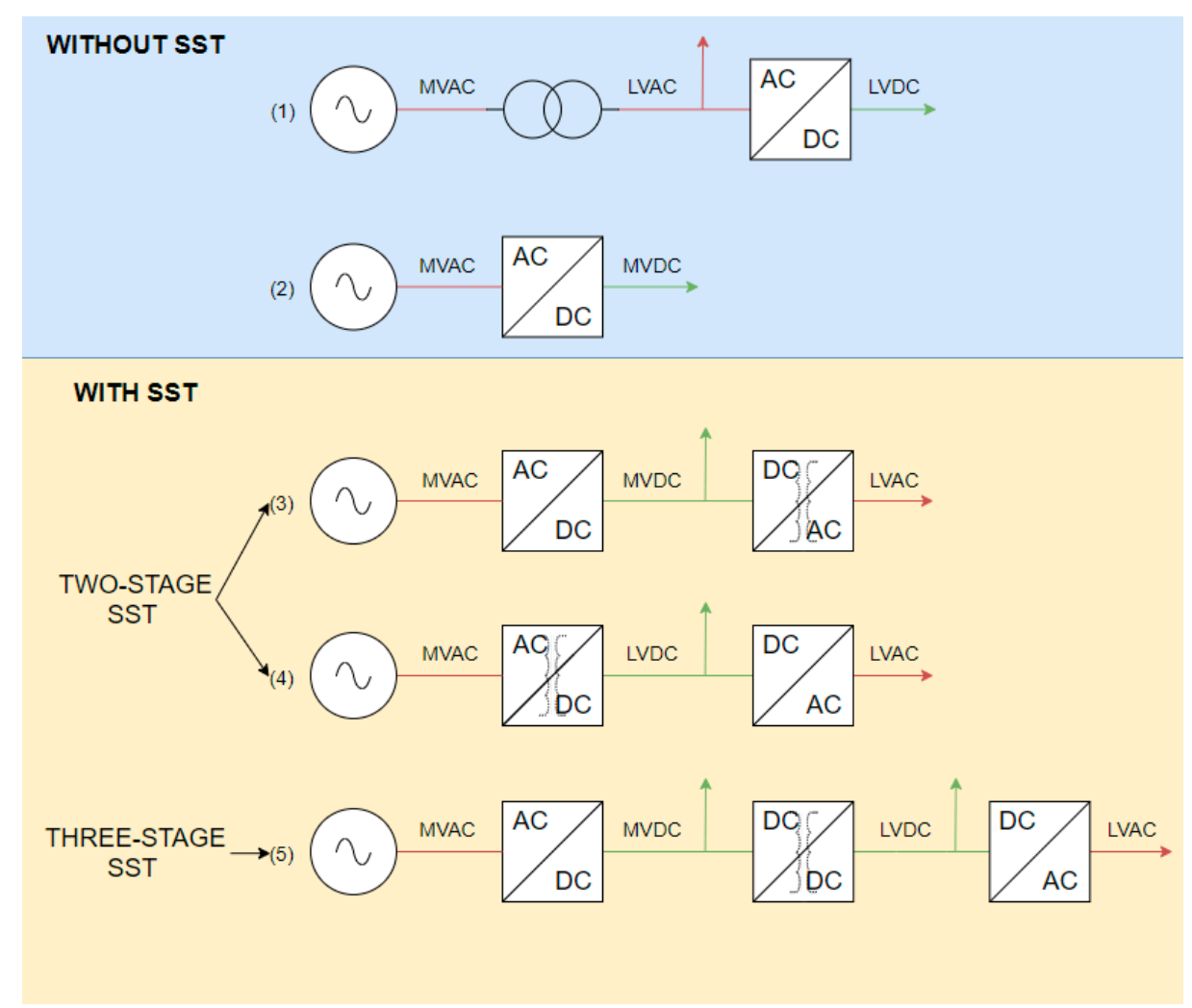

Figure 2. Interfaces between the DC MG and the main grid.

As regards the interfaces that do not include a SST, there are two main configurations, i.e., (1) and (2) as presented in Figure 2 (top part). The first one establishes a LVDC distribution line, utilizing a distribution transformer and an AC/DC converter. The distribution transformer provides the LVDC MG with galvanic isolation. Furthermore, it provides the capability for the implementation of a LVAC line, coupled with the MVAC grid (with galvanic isolation too, due to the distribution transformer). The second one establishes a MVDC distribution line, utilizing only an AC/DC converter. In this case, there is no galvanic isolation nor the capability to provide a LVAC distribution line. However, this interface may be suitable for the implementation of a MVDC MG cluster that connects two remote AC grids, enhancing their stability. The above configurations have been researched by the authors of [24,25], considering RES/BESS integration in the LV level, but also by the authors of [26], considering WG integration in the MV level.

Nevertheless, such interfaces seem, at present, outdated when compared to the SST interfaces. As seen in Figure 2 (bottom part), these can be divided in two main categories, the two-stage SST and the three-stage SST. As regards the two-stage SST, there are two main configurations, i.e., (3) and (4). The first one provides a MVDC link while the second one provides a LVDC link, both utilizing an AC/DC conversion stage as well as a DC/AC conversion stage. The main difference is the point where the voltage level is transformed. In the first case, the voltage is transformed from MV to LV in the (second) DC/ AC stage, which means that there is no galvanic isolation in the side of the MVDC MG. On the other hand, in the second case, the voltage is transformed in the (first) AC/DC stage, which means that the produced LVDC line has galvanic isolation. It is also noted that in both cases the SST provides the capability for implementation of a LVAC line that has galvanic isolation (due to the transformation of the voltage level) and is decoupled from the main MVAC grid (due to the mediation of the DC MG), which inhibits the propagation of disturbances. Researchers have studied both configurations, as presented in the work of $[27,28]$. 
Yet, the most popular out of all configurations is the three-stage SST, presented in Figure 2. This configuration is considered to be more sophisticated and technologically advanced than the previous configurations [29]. It includes an AC/DC conversion stage, a $\mathrm{DC} / \mathrm{DC}$ conversion stage and a DC/AC conversion stage. Therefore, it provides all three possible links and voltage levels, i.e., MVDC, LVDC and LVAC. Its complex composition has the unique advantage of providing links for all types of inputs/outputs. Yet, since it provides a MVDC link, the transformer needs to be located after the MV AC/DC converter. This means that galvanic isolation is only provided for the LVDC and LVAC lines. The design of a three-stage SST has gained a lot of attention over the past few years, due to the advantages it provides. Research and development work is conducted regarding the optimization of its operation, the improvement of its efficiency, the enhancement of its reliability and, of course, the reduction in its cost and size. In this context, special attention is paid to the Dual Active Bridge (DAB) (i.e., a bidirectional DC/DC converter with identical full bridges on its primary and secondary side and a high frequency transformer being the set of power electronics responsible for converting MVDC to LVDC in a three-stage SST), the minimization of the core's volume, losses and cost, and the optimal incorporation of the three-stage SST in modern applications [30,31]. Such applications include a wide range of scales, from smart buildings up to entire distribution systems [32-34].

All interfaces presented above provide the capability for the incorporation of a DC MG in the MVAC grid. However, some of them have characteristics that others lack, and no configuration meets all evaluation criteria to the highest level. Table 2 summarizes the basic criteria and their potential of fulfilment for each configuration that has been reviewed. It is noted that the configurations without SST require lower maintenance and have a lower cost than the SST configurations. The features that give them a comparable advantage make them a "safe" option with well-tested and established expectations. On the other hand, the SST configurations exceed in electronics technology (scalability, modularity, controllability) and also provide the capability for decoupled LVAC distribution. Especially, the three-stage SST is the only configuration able to facilitate the integration of MVDC, LVDC and LVAC MGs, including a variety of flexible capabilities. These attributes are the means required for achieving the goals of the future grids, i.e., smart grids, DC MGs, AC/DC hybrid MGs, etc.

Table 2. Evaluation of interfaces (Data from [21,29]).

\begin{tabular}{|c|c|c|c|c|c|}
\hline & \multicolumn{2}{|c|}{$\begin{array}{c}\text { Without SST } \\
\text { Configurations (1) and (2) }\end{array}$} & \multicolumn{3}{|c|}{$\begin{array}{c}\text { With SST } \\
\text { Configurations (3), (4) and (5) }\end{array}$} \\
\hline & (1) & (2) & (3) & (4) & (5) \\
\hline Integration of MVDC MG & No & Yes & Yes & No & Yes \\
\hline Integration of LVDC MG & Yes & No & No & Yes & Yes \\
\hline $\begin{array}{l}\text { Advanced power electronics } \\
\text { (scalability, modularity, } \\
\text { controllability) }\end{array}$ & No & No & Yes & Yes & Yes \\
\hline Galvanic isolation & Yes & No & No & Yes & $\begin{array}{l}\text { Yes, but not for } \\
\text { MVDC MG }\end{array}$ \\
\hline Cost & Low & Low & High & High & High \\
\hline Maintenance requirements & Low & Low & Medium & Medium & High \\
\hline $\begin{array}{c}\text { Capability for LVAC } \\
\text { distribution }\end{array}$ & Yes (coupled) & No & Yes (decoupled) & Yes (decoupled) & Yes (decoupled) \\
\hline
\end{tabular}

\section{Topologies of DC MGs}

As regards the topologies of a DC MG, five (5) main types can be distinguished: (a) single-bus, (b) radial, (c) ring, (d) mesh and (e) interconnected [19]. This section aims to analyze and compare the aforementioned types of topologies. 


\subsection{Single-Bus}

The general concept of the single-bus configuration is presented in Figure 3 [35]. In this type of configuration, the main characteristic is that there is only one DC bus and one point of connection between the components of the system, i.e., loads, generation units, storage units and the interface with the AC distribution network. Its main highlight is its simplicity, its low cost and low maintenance requirements. However, when it comes to flexibility in terms of fault management, the single-bus configuration has very limited options. This type of configuration appears in various studies, as for example in the work of [36-38], where single-bus DC MGs constitute test grids for the implementation of DC MG control schemes, demonstrating the single-bus capability for simple integration of RES and efficient operation.

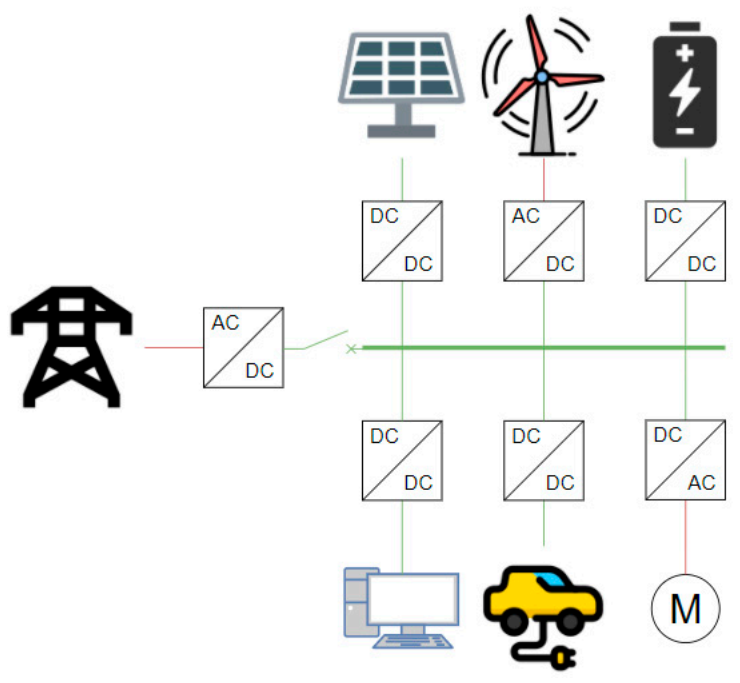

Figure 3. Single-bus configuration.

\subsection{Radial}

The general concept of a radial configuration includes a number of DC buses connected with each other without forming loops, having only one way of connection between the MG's interface and each component of the MG. The radial configuration is divided in two main sub-categories, i.e., a series configuration and a parallel configuration [19].

The general topology of a series configuration is presented in Figure 4. It is noted that there are two (or more) DC buses, each of which directly serves a combination of load, generation, storage and supply units. The first DC bus is directly connected to the interface between the DC MG and the main grid. However, the second DC bus is only connected to the first DC bus, through a DC power cable, with the appropriate switching and protection devices. In this way, if a fault occurs to the DC grid, the faulty part can be isolated, giving to the rest of the grid the possibility to operate normally. Obviously, the proposed configuration can be extended to more than two buses, according to the system's requirements. 


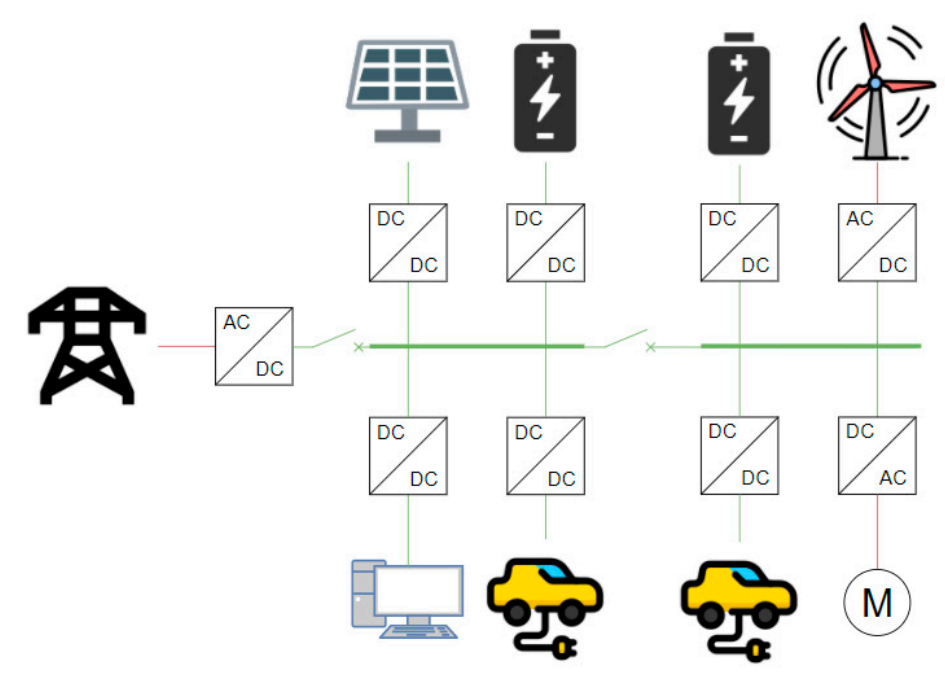

Figure 4. Radial series configuration.

On the other hand, the topology of the parallel configuration is presented in Figure 5. In this case, the DC buses are not connected with each other. Instead, both of them are connected, through power cables, to the power electronics converter interfacing the DC MG and the main AC grid. In this way, if a fault occurs on one bus of the DC MG, then the other bus of the grid will remain connected to the main grid, maintaining the ability of safe and normal operation. For this reason, this solution is considered to be more reliable than the series configuration. The parallel configuration can also be extended to a higher number of buses, depending on the system's requirements. When it comes to parallel configurations including more than two DC buses, an advantage over its series counterpart is the ability to share power between buses even in the instance of a fault that would isolate one or more DC buses. This feature highlights the power sharing capability of the parallel configuration.

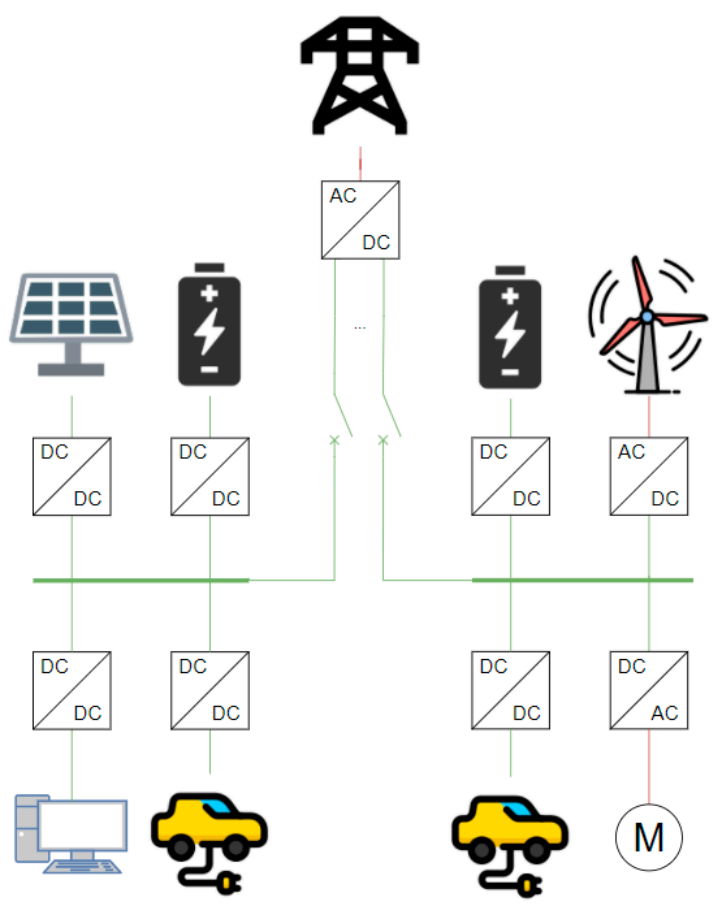

Figure 5. Radial parallel configuration. 
Overall, the radial configuration constitutes a simple and cost-effective solution, with low maintenance requirements but limited flexibility/fault management options. It has been extensively researched in many applications of DC MGs, from single smart buildings up to district level, mostly due to its simplicity. For example, the authors of [39] study the power sharing capability of an extensive radial DC MG with high DER penetration, while the authors of [40] study the radial DC MG configuration as part of a hybrid AC/DC MG consisting of RES, i.e., PV panels and WGs, EVs, DC and AC equipment.

\subsection{Ring}

In spite of the advantages of radial distribution described above, there are certain limitations that pose a challenge in terms of flexibility and fault management. In order to overcome the limitations of the radial configuration, a more complex topology, i.e., the ring configuration, has been introduced. The main concept of the ring configuration is presented in Figure 6. The proposed solution includes the placement of all loads, generation and storage units, interconnected along one single ring. For safety reasons, protection switches are located before and after the integration of each bus. This means that each component has two possible ways of connection with the interface between the DC MG and the main grid, i.e., through the line on its left-hand side and through the line on its right-hand side. The ring configuration provides the DC MG with flexibility, meaning that in case a fault occurs, the respective switches isolate it, allowing all units to maintain their functionality, except for the faulty one [18]. The ring configuration appears in a number of studies over the past few years. For example, the authors of [41-43] have studied protection schemes, fault detection and reconfiguration on DC MGs with ring configuration, especially due to their capability for advanced fault management.

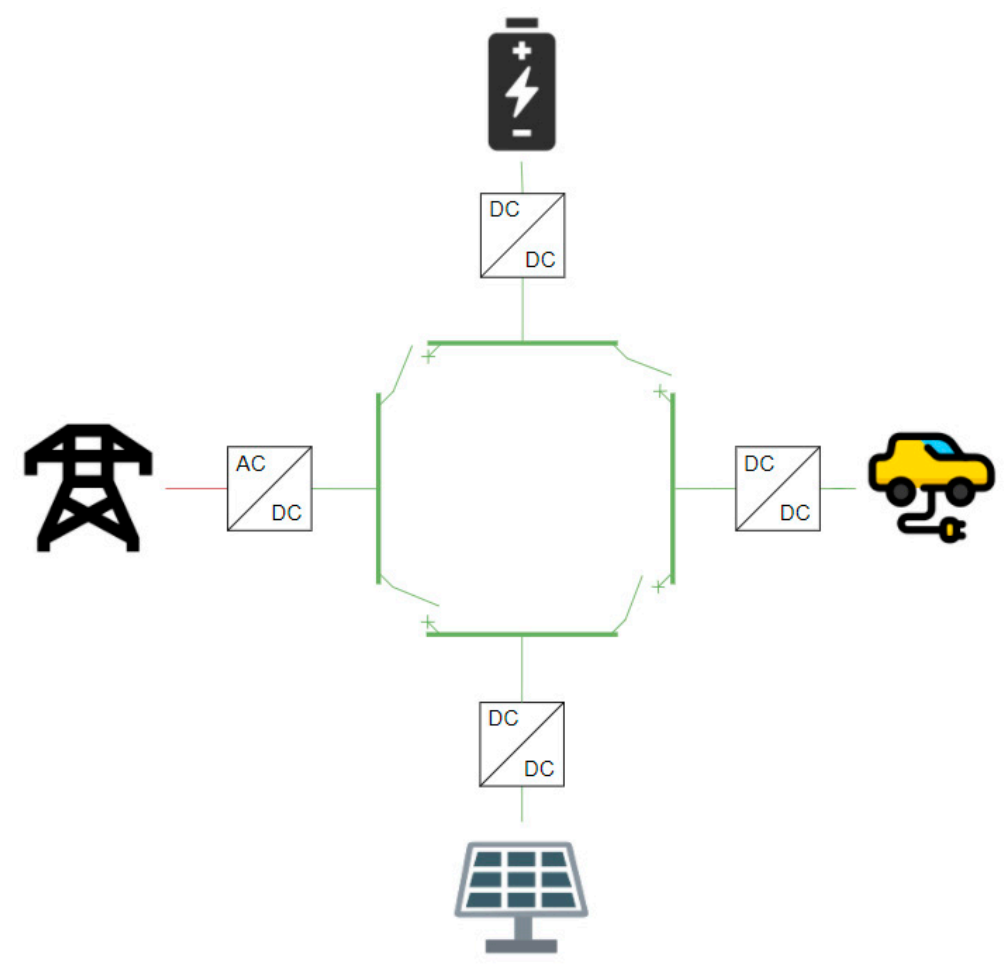

Figure 6. Ring configuration.

\subsection{Mesh}

The radial and ring configuration can be combined in a mesh configuration, as presented in Figure 7. The mesh configuration constitutes a complex topology that has partly the simplicity of the radial configuration and partly the flexibility of the ring configuration. Although its deployment is quite rare, several researchers have studied the capabilities that 
it provides. For instance, in [33,44,45], DC MGs with mesh configurations are presented. More specifically, in [45] an interesting aspect regarding the architecture of MGs is developed. In fact, the authors study mesh configurations of AC MGs, DC MGs, hybrid AC/DC MGs but also bilayer MGs. The latter constitute a new design for future grids, where each node is allowed to be universal, meaning that it can include two buses (AC and DC).

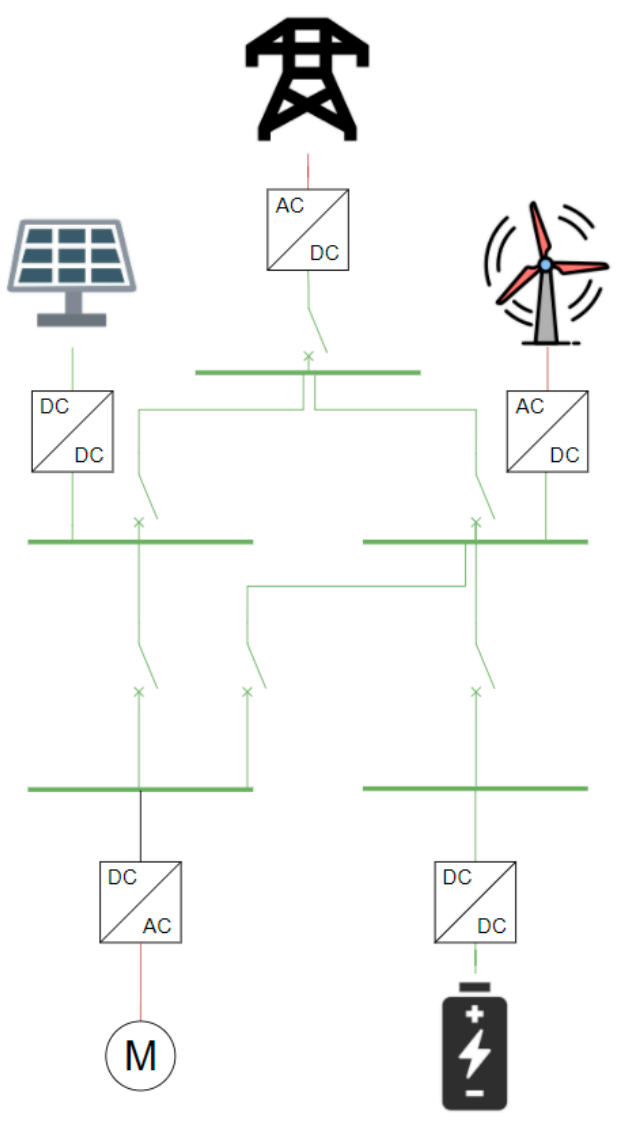

Figure 7. Mesh configuration.

\subsection{Interconnected}

Nevertheless, the aforementioned types of configurations have one common disadvantage. Due to their single connection to the main grid, if a fault occurs on the main grid, there is no possible way for the DC MG to absorb power. In order to tackle this issue, the interconnected configurations are formed, including more than one interface between the MG and the main power supply, which renders them by far more reliable in terms of fault management than all of the topologies previously described. Obviously, the increased flexibility they possess is reflected in the cost of increased complexity [20]. Although there are many ways to implement more than one connection between the MG and the main power supply, the most popular is the zonal configuration, presented in Figure 8. In this case, the DC MG is divided into a number of zones, each of which interacts with the rest of the MG through two buses, one at each side. The MG contains more than one interface with the utility grid. This configuration is completed by a number of switches that enable a variety of energy mixes as well as a number of solutions, in terms of reconfiguration, in case a fault occurs. This configuration is characterized by symmetry and reliability but also by complexity. Research on zonal configuration has been conducted by the authors of [46-48], all of who apply this configuration in relation to ships. 


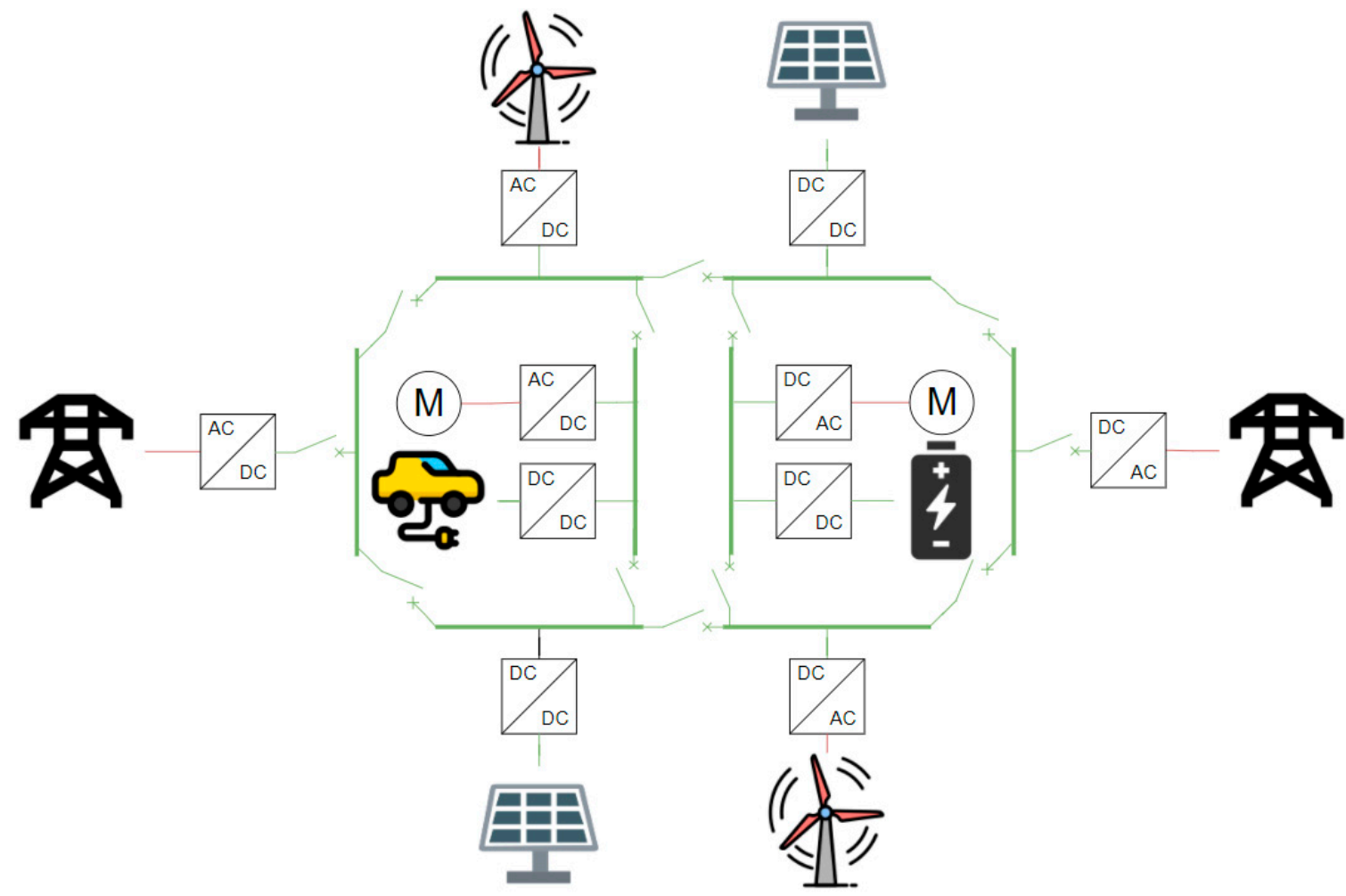

Figure 8. Zonal configuration.

4.6. Synopsis and Comparison among the Topologies

Table 3 summarizes all described features along with the classification of each topology. It can be stated that the flexibility of a topology, in terms of fault management and acquisition of power supply, is inversely proportional to its simplicity and cost effectiveness, as one could expect. Consequently, the selection of topology at the stage of design of a DC MG needs to be made according to its needs and available means of development.

Table 3. Evaluation of topologies (Data from [18-20,35,45]).

\begin{tabular}{cccccc}
\hline Features & Single-Bus [35] & Radial [19] & Ring [18] & Mesh [20,45] & Interconnected [20] \\
\hline Cost & Very low & Low & Medium & Medium & High \\
\hline $\begin{array}{c}\text { Simplicity } \\
\text { Maintenance }\end{array}$ & Very high & High & Medium & Medium & Medium \\
\hline $\begin{array}{c}\text { Fault management } \\
\text { capability }\end{array}$ & Very low low & Low & Medium & Medium & High \\
\hline $\begin{array}{c}\text { Easy integration of } \\
\text { remote RES }\end{array}$ & No & Low & Yes & Yes & Yes \\
\hline $\begin{array}{c}\text { Capability for } \\
\begin{array}{c}\text { continuous supply } \\
\text { from utility }\end{array}\end{array}$ & No & Yes & No & No & Yes \\
\hline $\begin{array}{c}\text { Reconfiguration } \\
\text { Main field }\end{array}$ & $\begin{array}{c}\text { Buildings, small } \\
\text { districts }\end{array}$ & Districts with RES & Districts with RES & Districts with \\
RES
\end{tabular}




\section{Control of DC MGs}

Apart from the selection regarding the interface with the main grid and the design of the topology for the connection of all the components included in the DC MG, it is essential to determine the control strategies according to which the total system will operate. The field of control strategies regarding these special structures has gained attention over the past few decades, which has led to the rise of advanced control algorithms, creating a mixture of different approaches presented in the worldwide literature [49-54]. Overall, control strategies deal with stability and protection issues, power balance, smooth transition regarding transient occurrences (e.g., black start), synchronization, optimization of various objectives (e.g., cost), market participation, etc. Three levels of hierarchical control of DC MGs can be distinguished, as presented in Figure 9 [55,56]:

1. Primary control: This is the lowest hierarchical control level and has the fastest response. It deals with the primary voltage regulation, the load sharing among the distributed generation of the MG and safety/protection issues. The respective DC/DC power converters of the MG undertake the above tasks.

2. Secondary control: While the primary control level is responsible for the primary voltage regulation, the secondary control level is responsible for the regulation of voltage fluctuations/deviations [55]. It is also responsible for the seamless reconnection of the MG to the main grid.

3. Tertiary control: This is the highest hierarchical control level. It sets the power flow between the DC MG and the main grid. It is also known as an energy management system (EMS) and communicates with the distribution system operator (DSO). In this sense, the DSO, or even the transmission system operator (TSO), may decide the power exchange with the MG.

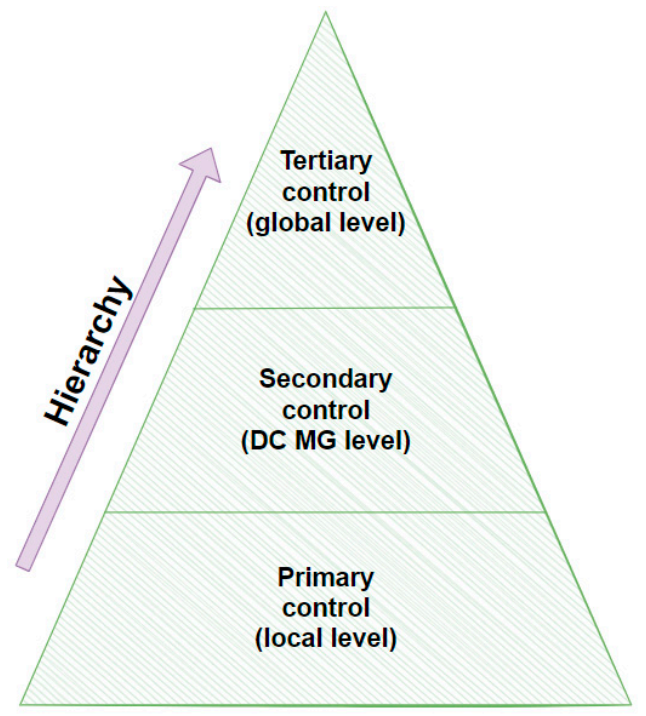

Figure 9. Hierarchical control.

The purpose of the primary/local control is to perform the current and voltage control of the power converters connected to the distributed generation and storage units and to be responsible for the load sharing among them, as presented in $[55,56]$. A vastly used local control system is the droop control method. The aim of droop control is to vary the reference values (voltage, amplitude, frequency, etc.) depending on the active and reactive power demand in order to share the load between the available devices. This control strategy originates from the power sharing of synchronous AC generators in conventional grids. In the case of DC structures, storage systems often incorporate this control system in order to perform optimal power sharing [57,58]. Also, there are cases where the control's objective may be the extraction of maximum power provided by the sources. A common 
example is the maximum power-point tracking (MPPT) mode, applied in wind turbine or PV systems [59,60]. Additionally, the master-slave strategy is considered to be widely adopted. This control strategy utilizes both voltage and current controllers in order to perform power sharing between the converters. The assigned master unit contains a voltage controller for the regulation of the voltage level and is responsible for the specification of a current reference of each slave unit. The slave units track the current reference given by the master unit and adapt to it through current controllers. In this way, the master-slave control performs current sharing with easy implementation, even with non-identical modules [61]. Altogether, the field of local control strategies in DC MGs has been extensively researched, as presented in the work of $[44,62,63]$.

As stated previously, above the primary control, in terms of hierarchy, there is the secondary control. Secondary level strategies can be distinguished in two types, namely: (a) centralized and (b) decentralized, depending on their location, as presented in Figure 10. The main difference is that in centralized techniques control actions are taken at a central point, whereas in decentralized techniques, which may or may not incorporate a communication network, control actions are taken at the local controller of each distributed power supply unit $[55,64]$.

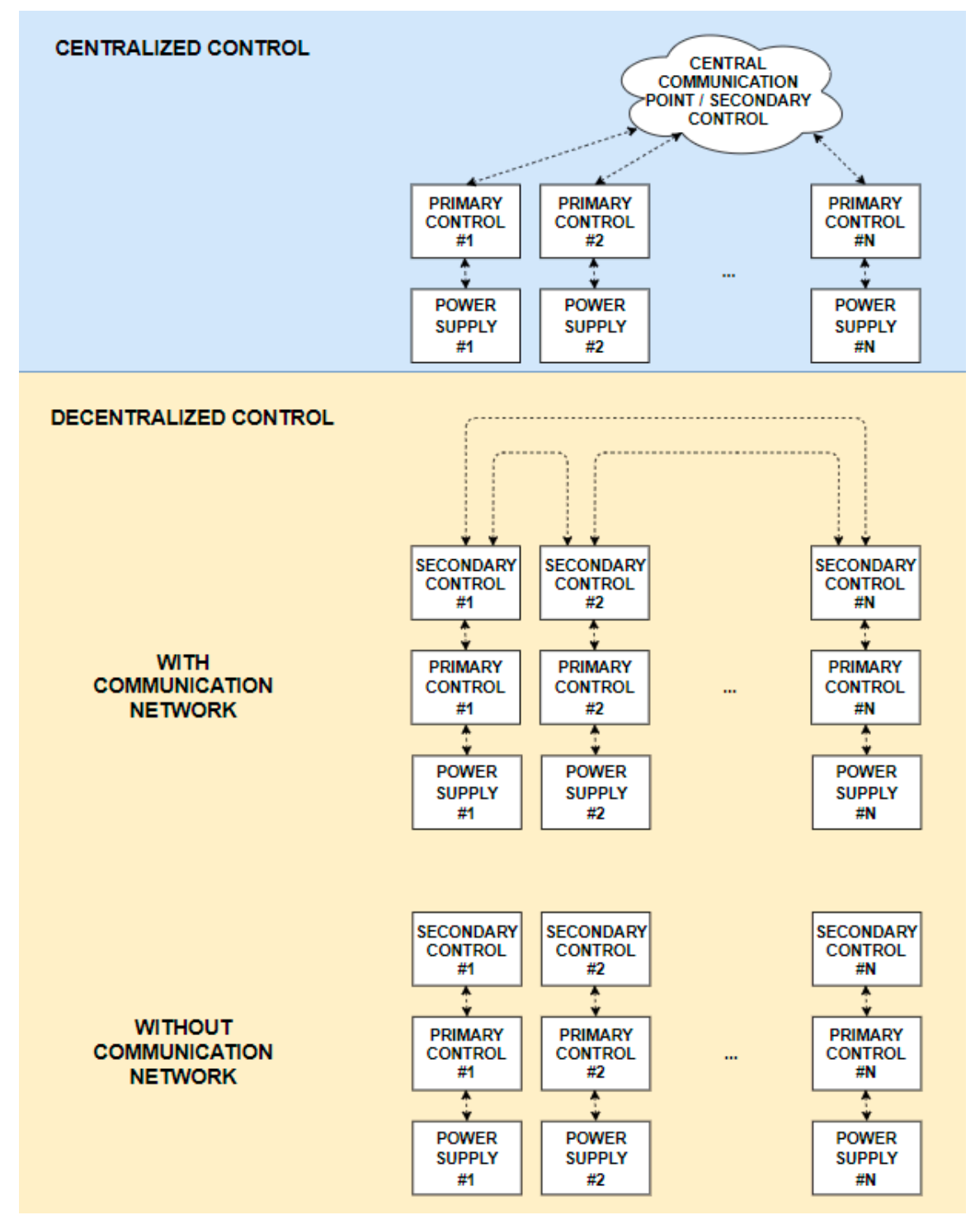

Figure 10. Secondary control strategies: centralized and decentralized (with/without communication network). 
As regards to centralized approaches, the management is performed from a central controller. The central controller needs to be connected to a communication system. In this way, the controller gathers information about the distributed generation and storage systems of the DC MG, such as active power measurements, voltage measurements, etc. Also, information regarding market conditions and requests from the upper (tertiary) control level are taken into account. Having processed the available data, the controller performs the necessary actions and provides references to the primary control level. This approach is suitable mostly for small scale DC MGs, where there exists a single owner of the distributed generation and storage units, providing the controller with clear, single tasks, thus avoiding conflicts of interest that would occur in the case of multiple owners [65,66].

Despite the efficiency of centralized control systems, the market is oriented towards MGs of a larger scale, including more than one provider of power supply units. For this purpose, decentralized control strategies are developed. These types of strategy require the implementation of secondary control in each unit separately/locally. Two main variations of this type of strategy are distinguished, i.e., with or without a communication system. In general, the decentralized control approach offers simple integration, meaning low communication requirements, facilitates the incorporation of multiple power supply producers and provides the ability for plug-and-play connection of devices. However, the operational pattern attained by this type of control is usually sub-optimal, since there are sometimes conflicts of interest between the owners of the power supply units, which means that some units may be competitive or have different kinds of goals with respect to others. Also, in contrast with the centralized control, due to the lack of centralized communication system, this DC MG operation cannot be attached to a larger and more critical operation [67-69].

The advantages and disadvantages of the two types of secondary level strategies are summarized and compared to each other in Table 4.

Table 4. Comparison between centralized and decentralized control (Data from $[56,65,67])$.

\begin{tabular}{ccc}
\hline & Centralized Control & Decentralized Control \\
\hline $\begin{array}{c}\text { Central communication and decision } \\
\text { point }\end{array}$ & Yes & No \\
\hline Suitable scale & Small & Large \\
\hline Purpose & Simple objectives & $\begin{array}{c}\text { Multiple objectives, } \\
\text { conflicts of interest }\end{array}$ \\
\hline $\begin{array}{c}\text { Complexity (communication, } \\
\text { installation, general requirements) }\end{array}$ & High & Low \\
\hline $\begin{array}{c}\text { Implementation of advanced } \\
\text { algorithms }\end{array}$ & Likely & Unlikely \\
\hline
\end{tabular}

However, when the DC MG does not operate in isolation, but in a grid-tied mode, the highest level of hierarchy is the tertiary control. Tertiary control is responsible for the energy management between the DC MG and the main grid, regulating the power exchanged between the two sides as well as the rest of the operational values and actions of the DC MG. This level of hierarchy establishes the reference values based on the requirements of the overall system, taking into consideration the status of the DC MG and the market. This includes the prices of energy, the state (e.g., state of charge) of the storage systems, the forecasts of RES production, the energy demand and possible ancillary services that can be offered by the DC MG. The data obtained can be utilized for the optimal schedule of operation, taking into consideration objectives such as cost minimization, power quality maximization, etc. In the literature, a great variety of hierarchical control architectures (i.e., including tertiary, secondary and primary control) is observed, including the implementation of economic dispatch algorithms, reduction in $\mathrm{CO}_{2}$ emissions, model predictive 
control (MPC) or even deep learning (DL) and deep reinforcement learning (DRL), for both normal operation and treatment of special challenges [70-73].

In conclusion, there is no standard way of control when it comes to DC MGs, mostly due to the fact that they do not have a standard form. This leads to a number of possible control architectures, depending on the size, the number of owners and the connection to/isolation from the main grid. Considering that this is a field of innovation, no optimal solution is provided for the control scheme of DC MGs in general. Each DC MG needs to have its control architecture designed individually, based on its assets and requirements.

\section{Applications of DC MGs}

Having analyzed the possible advantages, types of interfaces, topologies and control strategies, the aim of this section is to showcase modern examples of applications of DC MGs.

\subsection{Ships and Other Marine Applications}

Ships constitute a special applications environment that provides the opportunity to highlight the benefits of DC MGs. This is a case where the ways to supply the necessary power are limited due to constraints imposed by the ship's needs such as (a) constant power availability (taking into consideration that the ship's power system operates in isolation), space and weight concerns (the installations responsible for ensuring that the ship has always available power must be as compact as possible due to the limited space available on ships) and (c) presence of pulse loads (the demand of which changes periodically, creating the need for power systems that can keep up with the fast changes in load demand).

In the worldwide literature, several researches related to DC MGs on ships are observed, as presented in [74-77]. The DC power system facilitates the integration of both DC power supply (BESS, etc.) and DC power demand (radar, etc.) on the ship. The zonal configuration is the predominant one in this type of applications, due to its flexibility. The voltage level is usually higher than $1 \mathrm{kV}$.

\subsection{Transport Applications}

Due to the high availability of DC motors and their ability to easily control their speed, railways initially used DC current and continue to do so to this day. Even buses are moving towards DC-based power for environmental reasons. Also, both motors and auxiliary circuits inside urban transport vehicles use DC current. This results in the urban transport system itself being, in many cases, a DC power system, drawing its power from the main city power system. Because current power systems of cities are mostly AC, $\mathrm{AC} / \mathrm{DC}$ conversion is needed to power urban transports.

Research on DC transportation has been conducted by a number of researchers, including [78,79]. More specifically, the authors of [78] demonstrated that a MVDC electrification system for the Paris-Strasbourg line is at least on par with the current AC one in terms of efficiency. It also allowed less installed power for substations, no phase shift between them, and required less power electronics and no autotransformer purchases. It should be noted that in transport applications the voltage level varies according to the application, yet some indicative vastly used values are $750 \mathrm{~V}, 1500 \mathrm{~V}$ and $3000 \mathrm{~V}$.

\subsection{Data Centers}

Data centers are extremely important facilities. In fact, their importance is rapidly escalating as time passes and the need for high capacity of information storage increases. Future data centers could require power levels up to a few MWs to operate. Most loads in data centers are electronic in nature and operate on DC current, which means that an $\mathrm{AC}$ system would lead to losses due to the necessary AC/DC conversion stage. Additionally, $\mathrm{AC} / \mathrm{DC}$ converters are more complex devices with higher volume and failure rates than $\mathrm{DC} / \mathrm{DC}$ converters. These problems of AC power systems supplying data centers along with the trend of using renewable energy sources such as solar panels and battery storage 
(both utilizing DC current) favor the adoption of a DC power system for data centers. According to [80], low voltage $(380 \mathrm{~V})$ powered DC data centers occupy $33 \%$ less floor space, are more efficient and have a $36 \%$ lower lifetime cost than AC ones. The authors of [81] claimed the optimal level of DC voltage to be $400 \mathrm{~V}$ (considered to be low voltage) and ensured $7 \%$ energy savings along with the other benefits of DC, such as the nonexistence of harmonics.

\subsection{Building Applications}

Due to environmental and economic concerns, PV systems are quite commonly installed at commercial buildings (shopping centers, offices, etc.), residential buildings, hospitals or even schools. Excess energy produced can be diverted to ESS that can supply power back to the grid if necessary. As PV and energy storage systems are installed within the building, they allow the minimization of transmission losses. Both these power sources provide DC power and usually help to supply a large number of loads inside the building. Also, a proportion of the load of a building utilizes DC power. For example, Light Emitting Diodes (LED), used for lighting with increased efficiency, operate on DC current. Furthermore, chargers, small DC motors, power electronics and other loads of the average building use DC current to operate. Due to the main grid being an AC one, these devices are required to include $\mathrm{AC} / \mathrm{DC}$ converters internally or, in the case of power sources such as PV systems and BESS, they require an external DC-AC converter. However, by adopting a DC power system for powering the building, the converters and their associated losses can be omitted.

It should be noted that a building's power system may incorporate both a DC and an AC MG (the first of which may facilitate the connection of DC sources and loads while the second one may facilitate the connection of AC loads to the main AC grid) or even be entirely DC [82-84]. In fact, according to the research of [83], commercial buildings that incorporate PV systems in combination with DC MGs use the PV generation $6 \%-8 \%$ more efficiently than traditional AC systems do.

\subsection{Lighting of Public Spaces and Roads}

As part of public works and services, older lighting equipment is replaced with efficient LED technology, lighting mostly public spaces, roads and highways. DC grids power the LED lighting system, allowing a financial gain, since public lighting is a significant public cost. This field of innovation has been approached by a number of researchers. For example, in [85] the authors propose the incorporation of vacuum switches in low voltage DC MGs that power LED-based road lighting, showcasing the efficiency and reliability of the overall structure. Additionally, in [86] a model for public DC lighting system is presented, including multiple DC MG clusters, each of which is equipped with LED lights, PVs and storage.

\subsection{Electric Vehicles and Charging Stations}

Sales of EVs are increasing day by day around the world due to the need to protect the environment from fossil fuel emissions. This has caused car manufacturers to focus on producing EVs, which in the near future will partly replace traditional fossil fuel powered vehicles. Since EVs need charging at regular intervals to operate and their batteries are inherently DC powered, it would be more beneficial to have DC EV charging stations instead of their AC counterparts. In fact, DC charging stations may charge EVs faster than AC charging stations, due to increased efficiency, and may also efficiently incorporate PV panels in order to be more friendly to the environment, as presented in the work of $[13,87]$.

\subsection{Industrial Applications}

MVDC MGs have applications in some industries, because their processes require DC power to operate. Such industries include those that process steel or chemicals or even automotive manufacturing. For example, DC innovative solutions are observed in the 
field of copper or zinc electro-winning installations, electric arc furnaces, etc. [79]. Also, there are cases where LVDC MGs are considered to be a solution, especially if the industry includes automated production lines and/or RES power supply $[79,88]$.

\subsection{Synopsis of Applications of DC MGs}

Table 5 summarizes the main modern applications of DC MGs, along with their voltage requirements and the purpose for which they have been developed (easier integration of DC supply, DC load or both) $[19,89,90]$. It is noted that there are applications where the voltage requirements have a wide range. For example, in the case of buildings, according to various researchers, the optimal voltage range varies from $48 \mathrm{~V}$ up to $400 \mathrm{~V}$, depending on the application (where the lowest values are usually proposed for residential buildings, while the highest values are usually proposed for commercial buildings) [91,92]. Also, there are applications where the voltage level may vary in such a way that both LVDC and MVDC architectures are acceptable, as in industry or transport, according to the size of the application. Nevertheless, it should be noted that in AC applications, there are not as many variations regarding voltage levels and other requirements, as voltage levels are customized. This is attributed to the fact that the DC MGs are a relatively new trend that lacks standardization and regulatory framework.

Table 5. Applications of DC MGs (Data from [19,79-81]).

\begin{tabular}{cccc}
\hline Application & Usual Voltage (V) & Voltage Level & $\begin{array}{c}\text { Developed for the Easier Integration } \\
\text { of DC Supply or DC Load }\end{array}$ \\
\hline Marine (Ships) & $>1000$ & Both LV and MV & Both (supply and load) \\
\hline Transport & Mainly 750, 1000, 3000 [79] & Both LV and MV & Load \\
\hline Data centers & $380-400[80,81]$ & Only LV & Usually load but sometimes both \\
\hline Buildings & $48-400$, depending on the & Opply LV & Both (supply and load) \\
\hline Lighting of public spaces & $24[19]$ & Only LV & Load \\
\hline EV charging station & $<600$ & Only LV & Load \\
\hline Industry & $>600$ & Both LV and MV & Usually load but sometimes both \\
\hline
\end{tabular}

\section{Ancillary Services}

Ancillary services are considered to be the specialty services and functions that facilitate and support the continuous flow of electricity so that the power supply does, in all cases, meet the demand. They are provided by the DSO or procured from other stakeholders and are essential for maintaining power quality, grid stability and security $[93,94]$. However, there is a lack of a general definition of these services because in every regulated zone they can be defined independently based on their own market rules. The most common ancillary services found in the literature include loss compensation, black start capability, control of voltage, frequency or reactive power, oscillation damping and congestion management [95-99]. Further analysis about each of the categories of ancillary services can be found in the works of [100-106].

The implementation of DC infrastructures in the architecture of existing AC grids can provide a number of possible functions that may improve the operation of the grid. DC MGs links may be used to strengthen weak points in the power system, to control power flow in the AC network and to provide increased controllability and flexibility to its operator. Most common ancillary services provided by DC MGs and, generally, by DC links, are presented in Figure 11 and can be summarized as follows [107]: 


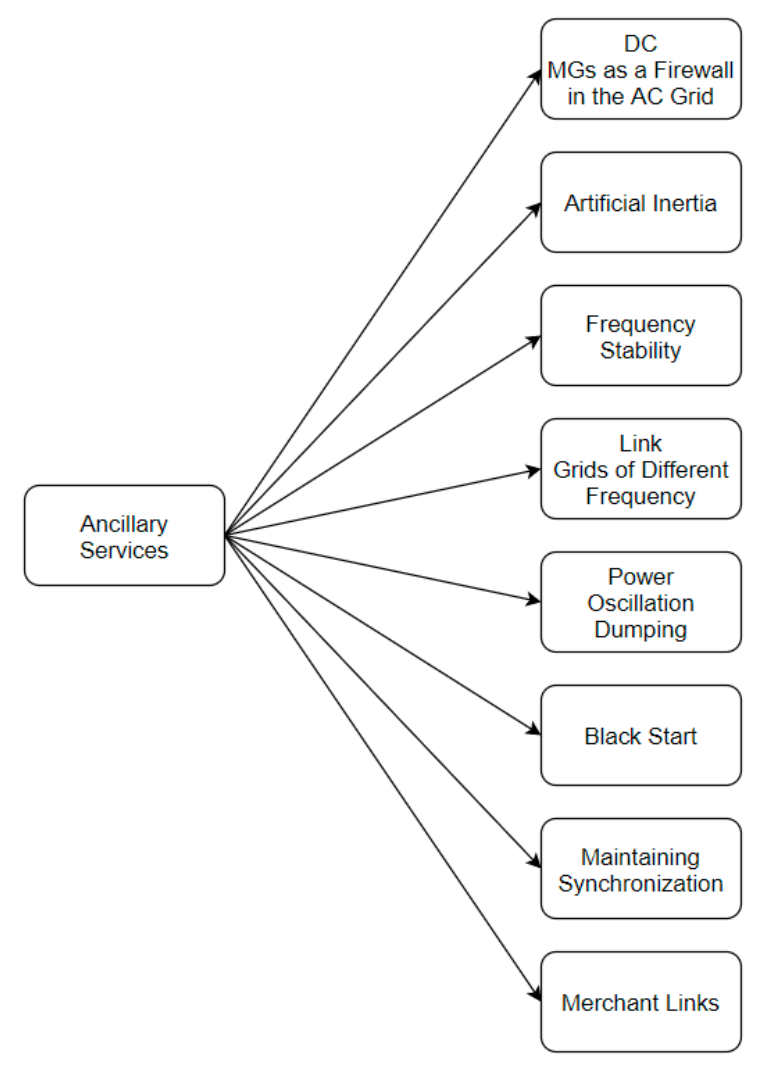

Figure 11. Ancillary services.

- DC MGs as a firewall in the AC grid: A DC system between AC grids can act as a "firewall" preventing disturbances spreading from one AC grid to another. When a power imbalance occurs on one part of the AC grid, the DC MG may mitigate the imbalance and prevent the disturbance from propagating to the rest of the network [104].

- Artificial inertia: Weak AC systems may suffer from frequency variations. This results from the low ratio of rotating mass (inertia) related to synchronous machines. In this case, the DC MGs can provide ancillary services by providing additional inertia in order to strengthen the local stability [100].

- Frequency stability: Frequency deviation in an AC grid results from imbalances between produced and consumed power. DC MGs, which have zero frequency, can mitigate the frequency deviation through their converters, thus restoring the frequency stability [101].

- Link grids of different frequency: A DC MG can act as a link between AC grids. The capability of DC systems to offer the desired frequency set-points makes possible the connection of AC grids with different frequencies [101].

- Power oscillation dumping: Electromechanical oscillations of the rotors in the synchronous machines may stress the main AC grid. These oscillations indicate an operating working point close to the stability limit that wears down the governor systems of the turbines. To reduce these oscillations and maintain a safe power transfer, a control signal can be applied to the DC system, which is considered to be a valuable ancillary service according to [105].

- Black-start: Black-start is considered to be an important ancillary service. Due to the interconnected power sources and storage means in a DC MG the restoration process (black-start) of an AC system can be fulfilled after a system power loss or blackout. Additionally, Voltage Source Converter (VSC) transmission technology can follow the cold load pickup as well as the pickup of the power production due to its smooth control of both active and reactive power [95]. 
- Maintaining synchronization: A DC MG system may provide ancillary services to the AC system by maintaining synchronization. DC systems can support the power flow in the AC grid, reducing the risk of falling out of step and losing synchronization, as presented in [101,104].

- Merchant links: The coupling of electricity markets and growing commercial interconnections requires precise, controllable power flows for effective operation, in line with the market-derived schedules. It is noted that, power scheduling on an hour or minute basis is a common situation. The controllability of active power flow in the DC systems guides the power flow in the AC system to fulfill prearranged commercial deals [107].

In short, by their very nature, modern DC MGs can be means for providing functionalities to the AC grid in a more controllable and efficient way. The integration of renewable sources as well as the possibility of energy storage act as a framework for the provision of specialized functions. The flexibility offered by a DC grid is evident in all areas of control of an AC grid. However, there is not yet a network code on MV-LV DC grid connection rules. A regulation on HVDC Connections and DC Connected Power Park Modules has been established by the EU [108] and that could be a starting point for a guideline on connection rules for MV and LV DC MGs.

\section{Future Trends and Challenges}

DC MGs are considered to be an innovative solution that shall facilitate the transition towards "green" energy $[35,109]$. In this sense, they are expected to be widely adopted in future applications related mainly to RES integration, EVs, data centers, etc.

However, in order to penetrate the market, they need to be further researched and developed [110-114]. In fact, since the DC system components have not been researched as much as their AC counterparts, it is natural that they still have parameters, such as cost, that need to be further optimized. For example, it is essential to increase the efficiency and power density of SSTs, DC/DC and AC/DC converters and reduce their cost.

Furthermore, it is critical to ensure the same level of safety of equipment and humans (workers, operators, etc.) as in the respective AC systems. Safety and reliability issues include switches and protection schemes, which are not as developed as their AC counterparts. Means to anticipate and overcome possible faults (fault detection and avoidance techniques) in the DC MG need to be thoroughly investigated before the large-scale deployment of such architectures [115-117].

Also, it is expected that in order for DC MGs to be fully effective, compatible equipment needs to be developed. In fact, one of the main reasons why the DC power systems are researched and developed is the ascending amalgamation of DC devices in the pool of loads that a distribution system feeds. Such devices include EVs, computers, power electronics systems, DC motors, etc. However, currently, these devices are powered by $\mathrm{AC}$ sources and have incorporated converters that convert the $\mathrm{AC}$ input to $\mathrm{DC}$ power in order to be served. In DC MGs this conversion, which reduces the efficiency of the grid, is not required. On the contrary, such DC loads are expected to be directly connected to DC lines. In order for these connections to be achieved, it is highly important to promote the development of DC-compatible equipment that is not yet available and suitable protection devices.

Of course, in order for DC MGs to be established, the appropriate regulatory framework needs to be developed. The lack of adequate standards is mostly observed in issues of DC voltage levels. So far, the research community has not agreed on one specific DC voltage level or even set clear limits between what is considered to be low, medium and high voltage, in terms of standardization. This issue needs to be addressed because without voltage standardization it is impossible to customize appliances, safety equipment and devices that are directly connected to DC buses. In fact, it is inconvenient for manufacturers to design DC products capable of operating on different voltage levels. In order to speed 
up the incorporation of DC technologies in the distribution grid, voltage standardization is by far the highest priority.

The existing standards have mostly been developed by the International Electrotechnical Commission (IEC) and the Institute of Electrical and Electronics Engineers (IEEE). A list of the most important contributions regarding standards and relative work that deal specifically or partly with MV and LV DC applications (and, therefore, DC MGs), developed by different entities/organizations, is presented in Table 6 [79]. The presented standards mostly refer to traction systems [118-121], ships [122,123], data centers [124], safety issues [125-128], LV and MV DC installations (in general) [129-132].

Table 6. Current standards addressing DC MGs (Data from [79,118-132]).

\begin{tabular}{|c|c|c|}
\hline Serial Number & Standard & Description \\
\hline \multicolumn{3}{|r|}{ Traction } \\
\hline 1 & IEC 60850 & Railway applications, supply voltages of traction systems \\
\hline 2 & IEC 60077-3 & Railway applications, electric equipment for rolling stock and rules for DC circuit-breakers \\
\hline 3 & IEC 61992-3 & $\begin{array}{l}\text { Railway applications, fixed installations, DC switchgear, DC disconnectors, } \\
\text { switch-disconnectors and earthing switches }\end{array}$ \\
\hline 4 & IEEE Std 1653.6 & $\begin{array}{c}\text { Recommended practice for grounding of DC equipment enclosures in traction power } \\
\text { distribution facilities }\end{array}$ \\
\hline \multicolumn{3}{|r|}{ Ships } \\
\hline 5 & IEEE 1709 & Recommended practice for $1-35 \mathrm{kV}$ Medium-Voltage DC power systems on ships \\
\hline 6 & MIL-STD-1399 & DC for submarines \\
\hline \multicolumn{3}{|r|}{ Data centers } \\
\hline 7 & EN 300 132-3-1 & Power supply interface for the input of telecommunications and datacom (ICT) equipment \\
\hline \multicolumn{3}{|r|}{ Safety } \\
\hline 8 & IEC 61660-1 & Calculation of short-circuit currents for DC installations in power plants and substations \\
\hline 9 & IEC 60204-11 & Safety of machinery for voltages above $1000 \mathrm{~V}$ AC or $1500 \mathrm{~V}$ DC and not exceeding $36 \mathrm{kV}$ \\
\hline 10 & IEC 60947-2 & LVDC switchgear and controlgear \\
\hline 11 & IEEE C37.14 & Standard for DC power circuit breakers used in enclosures (voltage lower than $3200 \mathrm{~V}$ ) \\
\hline \multicolumn{3}{|r|}{ LV and MV DC installations } \\
\hline 13 & IEC TS 61936-2 & Design of power installations exceeding $1.5 \mathrm{kV}$ DC \\
\hline 14 & IEC 60364-1 & $\begin{array}{l}\text { Fundamental principles, assessment of general characteristics and definitions for LV electrical } \\
\text { installations }\end{array}$ \\
\hline 15 & IEEE 946-2020 & Recommended practice regarding the design of DC power systems in stationary applications \\
\hline 16 & IEEE 1547 & Requirements for interconnecting distributed resources with electric power systems interfaces \\
\hline
\end{tabular}

As presented above, there is a variety of standards for different purposes that facilitate the integration of DC MGs into future grids. Nevertheless, this list is far from complete. There is a growing need for new standard developments, including all aspects of DC MGs, such as standards on voltage levels, grounding, safety, specialized standards regarding each application, etc. [20,79]. This need poses a great challenge that should be properly addressed for the wider adoption of DC MGs by the worldwide market.

\section{Conclusions}

This review paper highlights the potential of LV and MV DC MGs in terms of sustainability and efficiency and analyzes various aspects of their implementation, such as interfaces with the main grid, topologies and control strategies. The most popular application fields of DC MGs are presented, including ships, transport, data centers, buildings, lighting installations, EV charging stations and modern industry. Furthermore, possible ancillary services from the DC MGs to the main grid are examined. However, in order for DC MGs to be widely adopted, an adequate and inclusive regulatory framework needs to be developed, since the existing standards do not cover all aspects of their implementation. The main contribution of this review paper is that, in contrast with the existing review 
papers on DC MGs, it addresses all of these issues, instead of only addressing a part of them.

Author Contributions: Conceptualization, M.F., F.S. and D.R.; methodology, M.F., F.S. and D.R.; writing - original draft preparation, M.F., D.T., F.S. and O.B.; writing—review and editing, M.F., F.S. and D.R.; visualization, M.F., D.T., F.S. and D.R.; supervision, F.S. and D.R.; project administration, D.R.; funding acquisition, D.R. and S.V. All authors have read and agreed to the published version of the manuscript.

Funding: This research has received funding from the European Union's Horizon 2020 research and innovation programme, TIGON (Towards Intelligent DC-based hybrid Grids Optimizing the Network performance), under grant agreement No 957769, https:/ / cordis.europa.eu/project/id/957769.

Institutional Review Board Statement: Not applicable.

Informed Consent Statement: Not applicable.

Data Availability Statement: Data sharing not applicable.

Conflicts of Interest: The authors declare no conflict of interest.

\section{References}

1. European Commission. State of the Union 2020; European Comission: Brussels, Belgium, 2020.

2. Agora Energiewende. European Energy Transition 2030: The Big Picture; Agora Engerweide: Berlin, Germany, 2019.

3. SolarPower Europe. EU Market Outlook for Solar Power/2019-2023; SolarPower Europe: Brussels, Belgium, 2019.

4. AL Shaqsi, A.Z.; Sopian, K.; Al-Hinai, A. Review of Energy Storage Services, Applications, Limitations, and Benefits. Energy Rep. 2020, 6, 288-306. [CrossRef]

5. Yang, Y.; Bremner, S.; Menictas, C.; Kay, M. Battery Energy Storage System Size Determination in Renewable Energy Systems: A Review. Renew. Sustain. Energy Rev. 2018, 91, 109-125. [CrossRef]

6. Freitas Gomes, I.S.; Perez, Y.; Suomalainen, E. Coupling Small Batteries and PV Generation: A Review. Renew. Sustain. Energy Rev. 2020, 126, 109835. [CrossRef]

7. Normark, B.; Shivakumar, A.; Welsch, M. DC Power Production and Consumption in Households. In Europe's Energy TransitionInsights for Policy Making; Elsevier: Amsterdam, The Netherlands, 2017; pp. 237-248. ISBN 978-0-12-809806-6.

8. Kamat, A.S.; Khosla, R.; Narayanamurti, V. Illuminating Homes with LEDs in India: Rapid Market Creation towards Low-Carbon Technology Transition in a Developing Country. Energy Res. Soc. Sci. 2020, 66, 101488. [CrossRef]

9. Alassi, A.; Bañales, S.; Ellabban, O.; Adam, G.; MacIver, C. HVDC Transmission: Technology Review, Market Trends and Future Outlook. Renew. Sustain. Energy Rev. 2019, 112, 530-554. [CrossRef]

10. Marzinotto, M.; Mazzanti, G.; Nervi, M. Ground/Sea Return with Electrode Systems for HVDC Transmission. Int. J. Electr. Power Energy Syst. 2018, 100, 222-230. [CrossRef]

11. Härtel, P.; Vrana, T.K.; Hennig, T.; von Bonin, M.; Wiggelinkhuizen, E.J.; Nieuwenhout, F.D.J. Review of Investment Model Cost Parameters for VSC HVDC Transmission Infrastructure. Electr. Power Syst. Res. 2017, 151, 419-431. [CrossRef]

12. Ramezanzadeh, S.P.; Mirzaie, M.; Shahabi, M. Reliability Assessment of Different HVDC Transmission System Configurations Considering Transmission Lines Capacity Restrictions and the Effect of Load Level. Int. J. Electr. Power Energy Syst. 2021, 128, 106754. [CrossRef]

13. Aggeler, D.; Canales, F.; Zelaya-De La Parra, H.; Coccia, A.; Butcher, N.; Apeldoorn, O. Ultra-Fast DC-Charge Infrastructures for EV-Mobility and Future Smart Grids. In Proceedings of the 2010 IEEE PES Innovative Smart Grid Technologies Conference, Gothenburg, Sweden, 11-13 October 2010; pp. 1-8.

14. Elsayed, A.T.; Mohamed, A.A.; Mohammed, O.A. DC Microgrids and Distribution Systems: An Overview. Electr. Power Syst. Res. 2015, 119, 407-417. [CrossRef]

15. Ploumpidou, E. Supporting the Transition to DC Micro Grids in the Built Environment 2017; Technische Universiteit Eindhoven: Eindhoven, The Netherlands, 2017.

16. General Electric Company. High Voltage Direct Current Systems; General Electric Company: New York, NY, USA, 2016.

17. RTE. PE Interface to AC Grid: Grid Forming Control for a More Resilient Transmission Grid, and a Flexible DC Connection of Grid Customers; RTE: Paris, France, 2020.

18. Ullah, S.; Haidar, A.M.A.; Hoole, P.; Zen, H.; Ahfock, T. The Current State of Distributed Renewable Generation, Challenges of Interconnection and Opportunities for Energy Conversion Based DC Microgrids. J. Clean. Prod. 2020, 273, 122777. [CrossRef]

19. Kumar, D.; Zare, F.; Ghosh, A. DC Microgrid Technology: System Architectures, AC Grid Interfaces, Grounding Schemes, Power Quality, Communication Networks, Applications, and Standardizations Aspects. IEEE Access 2017, 5, 12230-12256. [CrossRef]

20. Chandra, A.; Singh, G.K.; Pant, V. Protection Techniques for DC Microgrid-A Review. Electr. Power Syst. Res. 2020, 187, 106439. [CrossRef] 
21. Unamuno, E.; Barrena, J.A. Hybrid Ac/Dc Microgrids-Part I: Review and Classification of Topologies. Renew. Sustain. Energy Rev. 2015, 52, 1251-1259. [CrossRef]

22. Ferreira Costa, L.; De Carne, G.; Buticchi, G.; Liserre, M. The Smart Transformer: A Solid-State Transformer Tailored to Provide Ancillary Services to the Distribution Grid. IEEE Power Electron. Mag. 2017, 4, 56-67. [CrossRef]

23. Falcones, S.; Ayyanar, R.; Mao, X. A DC-DC Multiport-Converter-Based Solid-State Transformer Integrating Distributed Generation and Storage. IEEE Trans. Power Electron. 2013, 28, 2192-2203. [CrossRef]

24. Patrao, I.; Figueres, E.; Garcerá, G.; González-Medina, R. Microgrid Architectures for Low Voltage Distributed Generation. Renew. Sustain. Energy Rev. 2015, 43, 415-424. [CrossRef]

25. Mandal, S.; Mandal, K.K. Optimal Energy Management of Microgrids under Environmental Constraints Using Chaos Enhanced Differential Evolution. Renew. Energy Focus 2020, 34, 129-141. [CrossRef]

26. Nguyen, T.-T.; Yoo, H.-J.; Kim, H.-M. A Comparison Study of MVDC and MVAC for Deployment of Distributed Wind Generations. In Proceedings of the 2016 IEEE International Conference on Sustainable Energy Technologies (ICSET), Hanoi, Vietnam, 14-16 November 2016; pp. 138-141.

27. Karabiber, A.; Keles, C.; Kaygusuz, A.; Alagoz, B.B. An Approach for the Integration of Renewable Distributed Generation in Hybrid DC/AC Microgrids. Renew. Energy 2013, 52, 251-259. [CrossRef]

28. Banaei, M.R.; Salary, E. Power Quality Improvement Based on Novel Power Electronic Transformer. In Proceedings of the 2011 2nd Power Electronics, Drive Systems and Technologies Conference, Tehran, Iran, 16-17 February 2011; pp. $286-291$.

29. Ordono, A.; Unamuno, E.; Barrena, J.A.; Paniagua, J. Interlinking Converters and Their Contribution to Primary Regulation: A Review. Int. J. Electr. Power Energy Syst. 2019, 111, 44-57. [CrossRef]

30. Nguyen, D.-D.; Nguyen, D.-H.; Ta, M.C.; Fujita, G. Sensorless Feedforward Current Control of Dual-Active-Bridge DC/DC Converter for Micro-Grid Applications. IFAC-Pap. Online 2018, 51, 333-338. [CrossRef]

31. Olowu, T.O.; Jafari, H.; Moghaddami, M.; Sarwat, A.I. Physics-Based Design Optimization of High Frequency Transformers for Solid State Transformer Applications. In Proceedings of the 2019 IEEE Industry Applications Society Annual Meeting, Baltimore, MD, USA, 29 September-3 October 2019; pp. 1-6.

32. Wang, Y.; Li, Y.; Cao, Y.; Tan, Y.; He, L.; Han, J. Hybrid AC/DC Microgrid Architecture with Comprehensive Control Strategy for Energy Management of Smart Building. Int. J. Electr. Power Energy Syst. 2018, 101, 151-161. [CrossRef]

33. Fotoohabadi, H.; Mohammadi, M. Evaluating the Technical Benefits of AC-DC Hybrid Distribution Systems Consisting of Solid-State Transformers Using a Multiobjective Index. Sustain. Energy Grids Netw. 2019, 18, 100224. [CrossRef]

34. Huang, L.; Li, Y.; Cui, Q.; Xie, N.; Zeng, J.; Shu, J. Research on Optimal Configuration of AC/DC Hybrid System Integrated with Multiport Solid-State Transforms and Renewable Energy Based on a Coordinate Strategy. Int. J. Electr. Power Energy Syst. 2020, 119, 105880. [CrossRef]

35. Dragicevic, T.; Lu, X.; Vasquez, J.C.; Guerrero, J.M. DC Microgrids-Part II: A Review of Power Architectures, Applications, and Standardization Issues. IEEE Trans. Power Electron. 2016, 31, 3528-3549. [CrossRef]

36. Hatahet, W.; Marei, M.I.; Mokhtar, M. Adaptive Controllers for Grid-Connected DC Microgrids. Int. J. Electr. Power Energy Syst. 2021, 130, 106917. [CrossRef]

37. Singh, P.; Lather, J.S. Power Management and Control of a Grid-Independent DC Microgrid with Hybrid Energy Storage System. Sustain. Energy Technol. Assess. 2021, 43, 100924. [CrossRef]

38. Liu, Z.; Zhao, J.; Zou, Z. Impedance Modeling, Dynamic Analysis and Damping Enhancement for DC Microgrid with Multiple Types of Loads. Int. J. Electr. Power Energy Syst. 2020, 122, 106183. [CrossRef]

39. Asad, R.; Kazemi, A. A Novel Distributed Optimal Power Sharing Method for Radial Dc Microgrids with Different Distributed Energy Sources. Energy 2014, 72, 291-299. [CrossRef]

40. Yu, H.; Niu, S.; Zhang, Y.; Jian, L. An Integrated and Reconfigurable Hybrid AC/DC Microgrid Architecture with Autonomous Power Flow Control for Nearly/Net Zero Energy Buildings. Appl. Energy 2020, 263, 114610. [CrossRef]

41. Abdali, A.; Mazlumi, K.; Noroozian, R. High-Speed Fault Detection and Location in DC Microgrids Systems Using Multi-Criterion System and Neural Network. Appl. Soft Comput. 2019, 79, 341-353. [CrossRef]

42. Meghwani, A.; Gokaraju, R.; Srivastava, S.C.; Chakrabarti, S. Local Measurements-Based Backup Protection for DC Microgrids Using Sequential Analyzing Technique. IEEE Syst. J. 2020, 14, 1159-1170. [CrossRef]

43. Tiwari, S.P.; Koley, E.; Ghosh, S. Communication-Less Ensemble Classifier-Based Protection Scheme for DC Microgrid with Adaptiveness to Network Reconfiguration and Weather Intermittency. Sustain. Energy Grids Netw. 2021, 26, 100460. [CrossRef]

44. Lee, G.-Y.; Ko, B.-S.; Lee, J.-S.; Kim, R.-Y. An Off-Line Design Methodology of Droop Control for Multiple Bi-Directional Distributed Energy Resources Based on Voltage Sensitivity Analysis in DC Microgrids. Int. J. Electr. Power Energy Syst. 2020, 118, 105754. [CrossRef]

45. Sallam, A.M.; Ahmed, H.M.A.; Salama, M.M.A. A Planning Framework for AC-DC Bilayer Microgrids. Electr. Power Syst. Res. 2020, 188, 106524. [CrossRef]

46. Ciezki, J.G.; Ashton, R.W. Selection and Stability Issues Associated with a Navy Shipboard DC Zonal Electric Distribution System. IEEE Trans. Power Deliv. 2000, 15, 665-669. [CrossRef]

47. Baran, M.E.; Mahajan, N. System Reconfiguration on Shipboard DC Zonal Electrical System. In Proceedings of the IEEE Electric Ship Technologies Symposium, Philadelphia, PA, USA, 27 July 2005; pp. 86-92. 
48. Feng, X.; Butler-Purry, K.L.; Zourntos, T. Real-Time Electric Load Management for DC Zonal All-Electric Ship Power Systems. Electr. Power Syst. Res. 2018, 154, 503-514. [CrossRef]

49. van der Blij, N.H.; Ramirez-Elizondo, L.M.; Spaan, M.T.J.; Bauer, P. Grid Sense Multiple Access: A Decentralized Control Algorithm for DC Grids. Int. J. Electr. Power Energy Syst. 2020, 119, 105818. [CrossRef]

50. Bandyopadhyay, S.; Ramirez-Elizondo, L.; Bauer, P. Stability Constrained Gain Optimization of Droop Controlled Converters in DC Nanogrids. In Proceedings of the 2018 International Power Electronics Conference (IPEC-Niigata 2018 -ECCE Asia), Niigata, Japan, 20-24 May 2018; pp. 1426-1434.

51. Van Der Blij, N.H.; Ramirez-Elizondo, L.M.; Spaan, M.T.J.; Bauer, P. Stability and Decentralized Control of Plug-and-Play DC Distribution Grids. IEEE Access 2018, 6, 63726-63736. [CrossRef]

52. Armghan, A.; Azeem, M.K.; Armghan, H.; Yang, M.; Alenezi, F.; Hassan, M. Dynamical Operation Based Robust Nonlinear Control of DC Microgrid Considering Renewable Energy Integration. Energies 2021, 14, 3988. [CrossRef]

53. Vasantharaj, S.; Indragandhi, V.; Subramaniyaswamy, V.; Teekaraman, Y.; Kuppusamy, R.; Nikolovski, S. Efficient Control of DC Microgrid with Hybrid PV_Fuel Cell and Energy Storage Systems. Energies 2021, 14, 3234. [CrossRef]

54. Trinh, P.-H.; Chung, I.-Y. Optimal Control Strategy for Distributed Energy Resources in a DC Microgrid for Energy Cost Reduction and Voltage Regulation. Energies 2021, 14, 992. [CrossRef]

55. Papadimitriou, C.N.; Zountouridou, E.I.; Hatziargyriou, N.D. Review of Hierarchical Control in DC Microgrids. Electr. Power Syst. Res. 2015, 122, 159-167. [CrossRef]

56. Unamuno, E.; Barrena, J.A. Hybrid Ac/Dc Microgrids-Part II: Review and Classification of Control Strategies. Renew. Sustain. Energy Rev. 2015, 52, 1123-1134. [CrossRef]

57. Lu, X.; Guerrero, J.M.; Sun, K.; Vasquez, J.C. An Improved Droop Control Method for DC Microgrids Based on Low Bandwidth Communication with DC Bus Voltage Restoration and Enhanced Current Sharing Accuracy. IEEE Trans. Power Electron. 2014, 29, 1800-1812. [CrossRef]

58. Guerrero, J.M.; Vasquez, J.C.; Matas, J.; de Vicuna, L.G.; Castilla, M. Hierarchical Control of Droop-Controlled AC and DC Microgrids-A General Approach toward Standardization. IEEE Trans. Ind. Electron. 2011, 58, 158-172. [CrossRef]

59. Zammit, D.; Staines, C.S.; Micallef, A.; Apap, M.; Licari, J. Incremental Current Based MPPT for a PMSG Micro Wind Turbine in a Grid-Connected DC Microgrid. Energy Procedia 2017, 142, 2284-2294. [CrossRef]

60. Priyadarshini, L.; Dash, P.K.; Dhar, S. A New Exponentially Expanded Robust Random Vector Functional Link Network Based MPPT Model for Local Energy Management of PV-Battery Energy Storage Integrated Microgrid. Eng. Appl. Artif. Intell. 2020, 91, 103633. [CrossRef]

61. Vandoorn, T.L.; De Kooning, J.D.M.; Meersman, B.; Vandevelde, L. Review of Primary Control Strategies for Islanded Microgrids with Power-Electronic Interfaces. Renew. Sustain. Energy Rev. 2013, 19, 613-628. [CrossRef]

62. Mortezapour, V.; Lesani, H. Hybrid AC/DC Microgrids: A Generalized Approach for Autonomous Droop-Based Primary Control in Islanded Operations. Int. J. Electr. Power Energy Syst. 2017, 93, 109-118. [CrossRef]

63. Arul, P.G.; Ramachandaramurthy, V.K.; Rajkumar, R.K. Control Strategies for a Hybrid Renewable Energy System: A Review. Renew. Sustain. Energy Rev. 2015, 42, 597-608. [CrossRef]

64. Ortiz, L.; González, J.W.; Gutierrez, L.B.; Llanes-Santiago, O. A Review on Control and Fault-Tolerant Control Systems of AC/DC Microgrids. Heliyon 2020, 6, e04799. [CrossRef]

65. Dragicevic, T.; Lu, X.; Vasquez, J.; Guerrero, J. DC Microgrids-Part I: A Review of Control Strategies and Stabilization Techniques. IEEE Trans. Power Electron. 2015, 31, 4876-4891. [CrossRef]

66. Li, P.; Guo, T.; Li, Y.; Han, X.; Wang, P.; Li, X.; Wang, Z. An Adaptive Coordinated Optimal Control Method for Parallel Bidirectional Power Converters in AC/DC Hybrid Microgrid. Int. J. Electr. Power Energy Syst. 2021, 126, 106596. [CrossRef]

67. Dimeas, A.; Tsikalakis, A.; Kariniotakis, G.; Korres, G. Microgrids Control Issues. In Microgrids; Hatziargyriou, N., Ed.; John Wiley and Sons Ltd.: Chichester, UK, 2013; pp. 25-80. ISBN 978-1-118-72067-7.

68. Aprilia, E.; Meng, K.; Zeineldin, H.H.; Hosani, M.A.; Dong, Z.Y. Modeling of Distributed Generators and Converters Control for Power Flow Analysis of Networked Islanded Hybrid Microgrids. Electr. Power Syst. Res. 2020, 184, 106343. [CrossRef]

69. Shafiee, Q.; Guerrero, J.M.; Vasquez, J.C. Distributed Secondary Control for Islanded Microgrids-A Novel Approach. IEEE Trans. Power Electron. 2014, 29, 1018-1031. [CrossRef]

70. Hu, J.; Shan, Y.; Guerrero, J.M.; Ioinovici, A.; Chan, K.W.; Rodriguez, J. Model Predictive Control of Microgrids-An Overview. Renew. Sustain. Energy Rev. 2021, 136, 110422. [CrossRef]

71. Beus, M.; Banis, F.; Pandžić, H.; Poulsen, N.K. Three-Level Hierarchical Microgrid Control—Model Development and Laboratory Implementation. Electr. Power Syst. Res. 2020, 189, 106758. [CrossRef]

72. Mazidi, M.; Rezaei, N.; Ardakani, F.J.; Mohiti, M.; Guerrero, J.M. A Hierarchical Energy Management System for Islanded Multi-Microgrid Clusters Considering Frequency Security Constraints. Int. J. Electr. Power Energy Syst. 2020, 121, 106134. [CrossRef]

73. Wu, T.; Wang, J. Artificial Intelligence for Operation and Control: The Case of Microgrids. Electr. J. 2021, 34, 106890. [CrossRef]

74. Faddel, S.; Saad, A.A.; Mohammed, O. Decentralized Energy Management of Hybrid Energy Storage on MVDC Shipboard Power System. In Proceedings of the 2018 IEEE Industry Applications Society Annual Meeting (IAS), Portland, OR, USA, 23-27 September 2018; pp. 1-7. 
75. Mills, A.J.; Ashton, R.W. Adaptive, Sparse, and Multi-Rate LQR Control of an MVDC Shipboard Power System with Constant Power Loads. In Proceedings of the 2017 IEEE International Conference on Industrial Technology (ICIT), Toronto, ON, Canada, 22-25 March 2017; pp. 498-503.

76. Vu, T.V.; Gonsoulin, D.; Perkins, D.; Papari, B.; Vahedi, H.; Edrington, C.S. Distributed Control Implementation for Zonal MVDC Ship Power Systems. In Proceedings of the 2017 IEEE Electric Ship Technologies Symposium (ESTS), Arlington, VA, USA, 14-17 August 2017; pp. 539-543.

77. Shekhar, A.; Ramirez-Elizondo, L.; Bauer, P. DC Microgrid Islands on Ships. In Proceedings of the 2017 IEEE Second International Conference on DC Microgrids (ICDCM), Nuremburg, Germany, 27-29 June 2017; pp. 111-118.

78. Verdicchio, A.; Ladoux, P.; Caron, H.; Courtois, C. New Medium-Voltage DC Railway Electrification System. IEEE Trans. Transp. Electrific. 2018, 4, 591-604. [CrossRef]

79. ABB. Medium Voltage Products, Technical Application Papers No. 24-Medium Voltage Direct Current Applications; ABB: Zurich, Switzerland, 2017.

80. AlLee, G.; Tschudi, W. Edison Redux: 380 Vdc Brings Reliability and Efficiency to Sustainable Data Centers. IEEE Power Energy Mag. 2012, 10, 50-59. [CrossRef]

81. Pratt, A.; Kumar, P.; Aldridge, T.V. Evaluation of 400V DC Distribution in Telco and Data Centers to Improve Energy Efficiency. In Proceedings of the 29th International Telecommunications Energy Conference, Rome, Italy, 30 September-4 October 2007; pp. 32-39.

82. Jhunjhunwala, A.; Lolla, A.; Kaur, P. Solar-Dc Microgrid for Indian Homes: A Transforming Power Scenario. IEEE Electrific. Mag. 2016, 4, 10-19. [CrossRef]

83. Fregosi, D.; Ravula, S.; Brhlik, D.; Saussele, J.; Frank, S.; Bonnema, E.; Scheib, J.; Wilson, E. A Comparative Study of DC and AC Microgrids in Commercial Buildings across Different Climates and Operating Profiles. In Proceedings of the 2015 IEEE First International Conference on DC Microgrids (ICDCM), Atlanta, GA, USA, 7-10 June 2015; pp. 159-164.

84. Li, W.; Mou, X.; Zhou, Y.; Marnay, C. On Voltage Standards for DC Home Microgrids Energized by Distributed Sources. In Proceedings of the Proceedings of The 7th International Power Electronics and Motion Control Conference, Harbin, China, 2-5 June 2012; Volume 3, pp. 2282-2286.

85. Liang, D.; Zou, J.; Wang, Z.; Yang, B. Research on DC Vacuum Switch of Micro-Grid in Road Lighting. In Proceedings of the 2018 2nd IEEE Advanced Information Management, Communicates, Electronic and Automation Control Conference (IMCEC), Xi'an, China, 25-27 May 2018; pp. 242-246.

86. Quintana, P.J.; Huerta, N.; Rico-Secades, M.; Calleja, A.J.; Corominas, E.L. Control of Public Dc Street/Road Lighting Microgrids with Microgeneration and Storage Capability Based on a Power-Line Signaling Dependent Droop. In Proceedings of the 2016 13th International Conference on Power Electronics (CIEP), Guanajuato, Mexico, 20-23 June 2016; pp. 98-103.

87. Vaidya, M.; Stefanakos, E.K.; Krakow, B.; Lamb, H.C.; Arbogast, T.; Smith, T. Direct DC-DC Electric Vehicle Charging with a Grid Connected Photovoltaic System. In Proceedings of the Conference Record of the Twenty Fifth IEEE Photovoltaic Specialists Conference-1996, Washington, DC, USA, 13-17 May 1996; pp. 1505-1508.

88. Senfelds, A.; Apse-Apsitis, P.; Avotins, A.; Ribickis, L.; Hauf, D. Industrial DC Microgrid Analysis with Synchronous Multipoint Power Measurement Solution. In Proceedings of the 2017 19th European Conference on Power Electronics and Applications (EPE'17 ECCE Europe), Warsaw, Poland, 11-14 September 2017; pp. P.1-P.6.

89. Ailway, R. ABB's Substation Installations for the Rail Industry Provide Reliable Power to the Line and the Vehicle, to Keep Main Line Trains, Metros and Mass Transit Networks on Track. Optimized Railway Electrification Solutions Ensure Availability and Dependability of AC and DC Power Supply to Enable High Performance and Efficiency; ABB Group: Zurich, Switzerland, 2017; p. 8.

90. California Energy Commission. Electric Vehicle Charging 101; California Energy Commision: Sacramento, CA, USA, 2021.

91. Siraj, K.; Khan, H.A. DC Distribution for Residential Power Networks-A Framework to Analyze the Impact of Voltage Levels on Energy Efficiency. Energy Rep. 2020, 6, 944-951. [CrossRef]

92. Anand, S.; Fernandes, B.G. Optimal Voltage Level for DC Microgrids. In Proceedings of the IECON 2010-36th Annual Conference on IEEE Industrial Electronics Society, Glendale, AZ, USA, 7-10 November 2010; pp. 3034-3039.

93. Feng, C.; Wang, S.; Mu, Q. Chapter 21 DC grid power flow control devices. In HVDC Grids: For Offshore and Supergrid of the Future; Wiley-IEEE Press: Hoboken, NJ, USA, 2016; p. 528. ISBN 978-1-118-85915-5.

94. ENTSO-E. Network Code for Requirements for Grid Connection Applicable to All Generators; ENTSO-E: Brussels, Belgium, 2013.

95. Hodel, C.; Beck, M. Overview of Ancillary Services, Switzerland. 2010. Available online: https://www.swissgrid.ch/dam/ swissgrid/customers/topics/ancillary-services/as-documents/AS-concept-V1-1-en.pdf (accessed on 29 July 2021).

96. Hirst, E.; Kirby, B. Electric-Power Ancillary Services. Oak Ridge Natl. Lab. 1996, 9, 26-30. [CrossRef]

97. Lavoine, O.; Regairaz, F.; Baker, T. Ancillary Services: An Overview of International Practices; Electra: Guilin City, China, 2009; Volume 252, pp. 86-91.

98. Renner, R.H.; Van Hertem, D. Ancillary Services in Electric Power Systems with HVDC Grids. IET Gener. Transm. Amp Distrib. 2015, 9, 1179-1185. [CrossRef]

99. Kaushal, A.; Hertem, D.V. An Overview of Ancillary Services and HVDC Systems in European Context. Energies 2019, $12,3481$. [CrossRef]

100. Tielens, P.; Van Hertem, D. The Relevance of Inertia in Power Systems. Renew. Sustain. Energy Rev. 2016, 55, 999-1009. [CrossRef] 
101. ENTSO-E. Need for Synthetic Inertia (SI) for Frequency Regulation. Available online: https:/ / consultations.entsoe.eu/systemdevelopment/entso-e-connection-codes-implementation-guidance-d-4/user_uploads/6---igd-on-si.pdf (accessed on 29 July 2021).

102. ENTSO-E. Balancing and Ancillary Services Markets. Available online: https://www.entsoe.eu/about/market/\#balancing-andancillary-services-markets (accessed on 29 July 2021).

103. Pentayya, P.; Gartia, A.; Das, A.P.; Kumar, C. Black Start Exercises Experience in Western Region, India. In Proceedings of the 2013 Annual IEEE India Conference (INDICON), Mumbai, India, 13-15 December 2013; pp. 1-5.

104. Corsi, S. Voltage Control and Protection in Electrical Power Systems; Springer: London, UK, 2015; pp. 163-190. ISBN 978-1-4471-6636-8.

105. Dominguez-Garcia, J.L.; Ugalde-Loo, C.E. Chapter 19 Power system oscillation damping by means of VSC-HVDC systems. In HVDC Grids: For Offshore and Supergrid of the Future; Wiley-IEEE Press: Hoboken, NJ, USA, 2016; p. 528. ISBN 978-1-118-85915-5.

106. Yusoff, N.I.; Zin, A.A.M.; Bin Khairuddin, A. Congestion Management in Power System: A Review. In Proceedings of the 2017 3rd International Conference on Power Generation Systems and Renewable Energy Technologies (PGSRET), Johor Bahru, Malaysia, 4-6 April 2017; IEEE: Johor Bahru, Malasyia, 2017; pp. 22-27.

107. ABB. Review HVDC Special Report. Available online: https://library.e.abb.com/public/aff841e25d8986b5c1257d380045703f/14 0818\%20ABB\%20SR\%2060\%20years\%20of\%20HVDC_72dpi.pdf (accessed on 27 July 2021).

108. Establishing a Network Code on Equirements for Grid Connection of High Voltage Direct Current Systems and Direct CurrentConnected Power Park Modules, Commission Regulation (EU) 2016/1447. Available online: https://eur-lex.europa.eu/eli/reg/ 2016/1447/oj (accessed on 29 July 2021).

109. PV Tech. The State of Medium Voltage DC Architectures for Utility-Scale PV; PV Tech: London, UK, 2020.

110. IEEE European Public Policy Initiative. DC Electricity Distribution in the European Union: An Opportunity for Energy Efficiency in Europe; IEEE: Piscataway, NJ, USA, 2017.

111. De Doncker, R.W. Energy System Transition and DC Hybrid Power Systems; RWTH Aachen University: Aachen, Germany, 2018.

112. Mo, R.; Li, R.; Li, H. Isolated Modular Multilevel (IMM) DC/DC Converter with Energy Storage and Active Filter Function for Shipboard MVDC System Applications. In Proceedings of the 2015 IEEE Electric Ship Technologies Symposium (ESTS), Old Town Alexandria, VA, USA, 21-24 June 2015; pp. 113-117.

113. SuperNode. Superconductors for Bulk Power Transfer; SuperNode: Dublin, Ireland, 2020.

114. Mackay, L.; Shekhar, A.; Roodenburg, B.; Ramirez-Elizondo, L.; Bauer, P. Series Arc Extinction in DC Microgrids Using Load Side Voltage Drop Detection. In Proceedings of the 2015 IEEE First International Conference on DC Microgrids (ICDCM), Atlanta, GA, USA, 7-10 June 2015; pp. 239-244.

115. Shekhar, A.; Mackay, L.; Ramirez-Elizondo, L.; Bauer, P. DC Microgrid Protection by Selective Detection of Series Arcing Using Load Side Power Electronic Devices. In Proceedings of the 2016 18th European Conference on Power Electronics and Applications (EPE'16 ECCE Europe), Karlsruhe, Germany, 5-9 September 2016; pp. 1-9.

116. Park, J.; Byun, H.; Kim, S.; Kim, S.; Won, C. DC Solid-State Circuit Breakers with Two-Winding Coupled Inductor for DC Microgrid. Energies 2021, 14, 4129. [CrossRef]

117. Grcić, I.; Pandžić, H.; Novosel, D. Fault Detection in DC Microgrids Using Short-Time Fourier Transform. Energies 2021, 14, 277. [CrossRef]

118. International Electrotechnical Commission. IEC 60850 Railway Applications-Supply Voltages of Traction Systems; International Electrotechnical Commission: Geneva, Switzerland, 2014.

119. International Electrotechnical Commission. IEC 60077-3:2019 Railway Applications-Electric Equipment for Rolling Stock-Part 3: Electrotechnical Components-Rules for DC Circuit-Breakers; International Electrotechnical Commission: Geneva, Switzerland, 2019.

120. International Electrotechnical Commission. IEC 61992-3:2006 Railway Applications-Fixed Installations-DC Switchgear-Part 3: Indoor d.c. Disconnectors, Switch-Disconnectors and Earthing Switches; International Electrotechnical Commission: Geneva, Switzerland, 2016.

121. IEEE Standards Association. IEEE 1653.6-2018-IEEE Recommended Practice for Grounding of DC Equipment Enclosures in Traction Power Distribution Facilities; IEEE: Piscatawy, NJ, USA, 2018.

122. IEEE Std 1709-2018 (Revision of IEEE Std 1709-2010): IEEE Recommended Practice for 1 KV to 35 KV Medium-Voltage DC Power Systems on Ships; IEEE: Piscataway, NJ, USA, 2018; ISBN 978-1-5044-5201-4.

123. MIL-STD-1399/390, Military Standard: Interface Standard for Shipboard Systems (Section 390) Electric Power, Direct Currnt, (Other Than Ship's Battery) for Submarines; Department of the Navy Naval Sea Systems Command: Washington, DC, USA, 1987.

124. Environmental Engineering (EE). Power Supply Interface at the Input to Telecommunications and Datacom (ICT) Equipment; Part 3: Operated by Rectified Current Source, Alternating Current Source or Direct Current Source up to 400 V.; Sub-Part 1: Direct Current Source up to $400 \mathrm{~V}$; Environmental Engineering (EE): Valbonne, France, 2011.

125. International Electrotechnical Commission. IEC 61660-1:1997 Short-Circuit Currents in d.c. Auxiliary Installations in Power Plants and Substations-Part 1: Calculation of Short-Circuit Currents; International Electrotechnical Commission: Geneva, Switzerland, 1997.

126. International Electrotechnical Commission. IEC 60204-11:2018 Safety of Machinery-Electrical Equipment of Machines-Part 11: Requirements for Equipment for Voltages above $1000 \mathrm{~V}$ AC or $1500 \mathrm{~V}$ DC and Not Exceeding $36 \mathrm{KV}$; International Electrotechnical Commission: Geneva, Switzerland, 2018.

127. International Electrotechnical Commission. IEC 60947-2 Low-Voltage Switchgear and Controlgear-Part 2: Circuit-Breakers; International Electrotechnical Commission: Geneva, Switzerland, 2003. 
128. IEEE Standards Association. IEEE C37.14-2015-IEEE Standard for DC (3200 V and below) Power Circuit Breakers Used in Enclosures; IEEE: Piscataway, NJ, USA, 2015.

129. International Electrotechnical Commission. IEC TS 61936-2:2015 Power Installations Exceeding 1 KV a.c. and 1.5 KV d.c.-Part 2: D.c.; International Electrotechnical Commission: Geneva, Switzerland, 2015.

130. International Electrotechnical Commission. IEC 60364-1 Low-Voltage Electrical Installations-Part 1: Fundamental Principles, Assessment of General Characteristics, Definitions; International Electrotechnical Commission: Geneva, Switzerland, 2005.

131. IEEE Standards Association. IEEE 946-2020-IEEE Recommended Practice for the Design of DC Power Systems for Stationary Applications; IEEE: Piscataway, NJ, USA, 2020.

132. IEEE Standards Association. IEEE 1547-2018-IEEE Standard for Interconnection and Interoperability of Distributed Energy Resources with Associated Electric Power Systems Interfaces; IEEE: Piscataway, NJ, USA, 2018. 